\title{
Overexpression of PDE4A Acts as Checkpoint Inhibitor Against cAMP-Mediated Immunosuppression in vitro
}

\begin{abstract}
Klaus G. Schmetterer ${ }^{1}$, Katrin Goldhahn ${ }^{1}$, Liesa S. Ziegler ${ }^{1}$, Marlene C. Gerner ${ }^{1}$, Ralf L. J. Schmidt ${ }^{1}$, Madeleine Themanns ${ }^{2}$, Eva Zebedin-Brandl ${ }^{2}$, Doris Trapin ${ }^{3}$, Judith Leitner ${ }^{3}$, Winfried F. Pickl ${ }^{3}$, Peter Steinberger ${ }^{3}$, Ilse Schwarzinger ${ }^{1}$ and Rodrig Marculescu ${ }^{\text {1* }}$
\end{abstract}

${ }^{1}$ Department of Laboratory Medicine, Medical University of Vienna, Vienna, Austria, ${ }^{2}$ Center of Physiology and Pharmacology, Institute of Pharmacology, Medical University of Vienna, Vienna, Austria, ${ }^{3}$ Center for Pathophysiology, Infectiology and Immunology, Institute of Immunology, Medical University of Vienna, Vienna, Austria

\section{OPEN ACCESS}

Edited by:

Katy Rezvani,

University of Texas MD Anderson Cancer Center, United States

Reviewed by:

Chao Wang

Brigham and Women's Hospital,

United States

Doug Clayton Palmer

National Cancer Institute (NCl),

United States

*Correspondence:

Rodrig Marculescu

rodrig.marculescu@meduniwien.ac.at

Specialty section:

This article was submitted to Cancer Immunity and Immunotherapy,

a section of the journal

Frontiers in Immunology

Received: 13 March 2019

Accepted: 16 July 2019

Published: 30 July 2019

Citation:

Schmetterer KG, Goldhahn K, Ziegler LS, Gerner MC, Schmidt RLJ,

Themanns M, Zebedin-Brandl E,

Trapin D, Leitner J, Pickl WF,

Steinberger $P$, Schwarzinger I and Marculescu R (2019) Overexpression of PDE4A Acts as Checkpoint Inhibitor Against CAMP-Mediated Immunosuppression in vitro. Front. Immunol. 10:1790. doi: 10.3389/fimmu.2019.01790
Malignant cells acquire physiological mechanisms of immunosuppression to escape immune surveillance. Strategies to counteract this suppression could help to improve adoptive immunotherapy regimen. The intracellular second messenger cyclic AMP (cAMP) acts as a potent immunosuppressive signaling molecule in T-cells and is up-regulated by multiple tumor-relevant suppressive factors including prostaglandin E2 (PGE2), adenosine and the functions of regulatory T-cells. Consequently, we aimed to abrogate cAMP signaling in human T-cells by ectopic overexpression of phosphodiesterase 4A (PDE4A). We could show that retroviral transduction of PDE4A into T-cells led to efficient degradation of CAMP in response to induction of adenylate cyclase. Retroviral transduction of PDE4A into $\mathrm{CD}^{+}{ }^{+}$and $\mathrm{CD}^{+}{ }^{+}$T-cells restored proliferation, cytokine secretion as well as cytotoxicity under immunosuppression by PGE2 and A2A-R agonists. PDE4A-transgenic T-cells were also partially protected from suppression by regulatory T-cells. Furthermore, PGE2-mediated upregulation of the inhibitory surface markers CD73 and CD94 on CD8 ${ }^{+}$T-cells was efficiently counteracted by PDE4A. Importantly, no differences in the functionality under non-suppressive conditions between PDE4A- and control-vector transduced T-cells were observed, indicating that PDE4A does not interfere with T-cell activation per se. Similarly, expression of surface markers associated with T-cell exhaustion were not influenced by PDE4A overexpression in long term cultures. Thus, we provide first in vitro evidence that PDE4A can be exploited as immune checkpoint inhibitor against multiple suppressive factors.

Keywords: immune tolerance, checkpoint inhibitor, adoptive immunotherapy, tumor immunosuppression, T-cell engineering

\section{INTRODUCTION}

One of the cardinal features of malignant processes is their ability to suppress anti-tumor immune responses, which allows them to escape the physiological tumor-immunosurveillance (1). To that end, malignant cells up-regulate mechanisms, which physiologically serve as regulators of adaptive immune responses. These measures include the overexpression of inhibitory ligands such as PD-L1, 
the secretion of immunomodulatory cytokines, metabolites (e.g., adenosine or kynurenines) and arachnidonic acid derivatives (e.g., PGE2) as well as the attraction, infiltration and accumulation of regulatory T-cells into the tumor stroma [reviewed in Vinay et al. (2)]. First successful clinical trials of melanoma patients with CTLA-4 and PD-1 inhibitors have highlighted the importance of these immune checkpoints for tumor growth as well as the potency of immune checkpoint blockade as therapeutic approach $(3,4)$ and currently numerous trials exploiting this principles are ongoing. Tumor-mediated immunosuppression also poses a major impediment in the development of adaptive immunotherapy protocols $(5,6)$. So far, most strategies to enhance the efficacy of T-cell therapy have aimed to improve tumor recognition by ectopic expression of tumor-antigen specific TCR or chimeric antigen receptors (CAR). In this respect, both approaches have shown great promise in various malignancies and recently first therapeutic applications of CAR T-cells have been approved by the FDA for the treatment of advanced ALL and B-NHL $(7,8)$ and have also been recommended by the EMA. However, it has become increasingly evident that other features of adoptively transferred T-cell therapies, such as trafficking, exhaustion, metabolic features and the response to suppressive modalities should also be targeted [reviewed in Sadelain et al. (9)]. Thus, recent studies on T-cell engineering have described modifications to overcome blockade of immunosuppressive signals in combination with antigen-recognition receptors (10-14). Advances in gene delivery systems have led to safe and clinically-approved protocols for the generation of engineered T-cells expressing multiple transgenes. Consequently, it can be envisioned that T-cells can be equipped with antigen-receptors as well as internal checkpoint inhibitors to guarantee optimal anti-tumor immunity. In this context, the definition of crucial immunoregulatory mechanisms, as well as measures to overcome their functions, should bear high therapeutic relevance.

Intracellular up-regulation of the second messenger cAMP acts as a common suppressive denominator for multiple extrinsic signals including PGE2 (15), adenosine (16), $\beta$-adrenergic agonists $(17,18)$, and histamine (19). Additionally, regulatory T-cells utilize cAMP to suppress effector T-cells either by production of adenosine $(20,21)$ or by direct transport through gap junctions into effector T-cells (22) [reviewed in Rueda et al. (23)]. The level of intracellular cAMP is regulated by the antagonizing actions of the adenylate cyclase (AC), generating cAMP, and phosphodiesterases (PDE), which degrade cAMP to $5^{\prime}$-AMP. High cAMP levels in T-cells result in low activity and tolerogenic function (24). Along those lines, regulatory $\mathrm{T}$ cells display high levels of CAMP due to up-regulation of AC9 (25) and down-regulation of PDE3B (26). Elevated cAMP levels promote distinct intracellular signaling events, whose net result is the suppression of effector functions such as proliferation, production of pro-inflammatory cytokines and cytotoxic activity of $\mathrm{CD}^{+}$T-cells. Activation of protein kinase A (PKA) is one key pathway, which is triggered by cAMP. In turn, PKA activation initiates multiple intracellular signaling pathways including activation of the C-terminal Src kinase (Csk) and the CRE modulator (CREM) and its alternative splice product, the inducible cAMP early repressor (ICER) [reviewed by Mosenden and Tasken (24)]. PKA also activates PDEs, possibly initiating a negative feedback loop, which lowers cAMP levels and returns effector T-cell to a responsive state. Furthermore, studies indicate that cAMP also triggers PKA-independent intracellular signaling pathways that contribute to the modulation of T-cell activation $(27,28)$. Thus, cAMP constitutes a molecular hub between extrinsic modulators and intracellular signaling pathways.

Several studies suggest that manipulation of the cAMPPKA axis can interfere with T-cell regulation. Pharmacological inhibitors of PDEs can enhance the regulatory capacity of Treg (29) while in contrast inhibition of AC or overexpression of $\mathrm{PDE} 4 \mathrm{C}$ in $\mathrm{CD} 4{ }^{+} \mathrm{CD} 25^{+}$Treg abrogates their suppressive function (30). Accordingly, PDE inhibitors have now been approved for the therapy of autoimmune and inflammatory diseases (31). On the other hand, cAMP-inducing signals strongly contribute to the immunosuppressive microenvironment of different tumors. Overexpression of the cyclooxygenase-2 (COX2 ), which leads to the enhanced production of PGE2, has been reported for more than $80 \%$ of colorectal carcinomas (32). Similarly, COX-2 expression has been correlated to poor outcome in breast cancer patients (33). A comprehensive study of more than 500 human cancer tissue samples has established, that CD39 accompanied by increased adenosine production can be found in diverse types of solid as well as hematological malignancies (34). Expression of CD39 and /or CD73 have been found described as major mechanisms of immune tolerance in CLL $(35,36)$. Furthermore, the preferential infiltration of adenosine-producing $\mathrm{CD} 9^{+}$Treg has been reported for solid tumors such as head and neck cancer (37), non-small cell lung cancer (38) and colorectal carcinomas (39) but also for hematological malignancies such as follicular lymphoma (40). Similarly, increased frequencies of adenosine-hydrolysing Treg were observed in peripheral blood of AML patients (41). Taken together, mechanisms which induce cAMP levels in tumorinfiltrating lymphocytes provide a major mechanism for the down-regulation of anti-tumor immune responses. Thus, cAMP can be considered as a highly relevant immune checkpoint.

In this proof of principle study, we aimed to restore T-cell activation in the presence of PGE2, adenosine or regulatory T-cells by ectopic overexpression of PDE4A. To that end, the human PDE4A cDNA was retrovirally transduced into $\mathrm{CD}^{+}{ }^{+}$and $\mathrm{CD}^{+}{ }^{+}$T-cells and their effector functions in the presence of the above described suppressive mechanisms were assessed in vitro.

\section{MATERIALS AND METHODS Ethical Considerations, Cell Isolation, and Culture}

The study was approved by the local ethics committee of the Medical University of Vienna (EC number 1724/2012) and conducted according to the Declaration of Helsinki (1969, including current revisions) of the World Medical Association. After obtaining informed consent of study participants, peripheral blood mononuclear cells (PBMC) were isolated from 
healthy volunteers by standard Ficoll paque centrifugation. Total $\mathrm{CD}^{+}{ }^{+}$-cells, $\mathrm{CD}^{+}{ }^{+}$and $\mathrm{CD} 8^{+}$T-cells were isolated from PBMC using the respective $\mathrm{T}$-cell Isolation Kits (Miltenyi Biotech, Bergisch Gladbach, Germany) according to the manufacturers' instructions. Purity was assessed by flow cytometric analyses using monoclonal antibodies against human CD3 (clone OKT3, eFluor 450 conjugated; eBioscience, San Diego, CA), human CD4 (clone OKT4, FITC conjugated; eBioscience) and human CD8 (OKT8, APC conjugated) and routinely found to be above 95\%. All functional assays were performed in IMDM (GE Healthcare, Piscataway, NJ) supplemented with $10 \%$ fetal calf serum (GE Healthcare), $10 \mu \mathrm{g} / \mathrm{mL}$ gentamycin and $1.25 \mu \mathrm{g} / \mathrm{mL}$ amphotericin B (both Sigma Aldrich, St. Louis, MO).

\section{Molecular Cloning}

The cDNA encoding human PDE4A was amplified from a human T-cell cDNA library using the following primers: PDE4A for $5^{\prime}-$ CCCGCGAAGCTTGCCACCATGGAACCCCCGACCGTCCC - 3', PDE4A rev $5^{\prime}$ - CCCGCGGCGGCCGCTTTAGGTA GGGTCTCCACCTGACCC - 3' (underlined sequences mark restriction enzyme sites). The cDNA was cloned into the pMMP-IRES-GFP vector using the restriction enzymes HindIII and NotI. The pMMP-FOXP3-IRES-GFP and the empty-control pMMP-IRES-GFP vector were described elsewhere (42).

\section{Transfection of HEK-293 Cells}

HEK-293 cells were transfected using the $\mathrm{Ca}_{2} \mathrm{PO}_{4}$ precipitation method as described previously (43). In short, for the production of amphotropic T-cell transducing retrovirus supernatants, 30 $\mu \mathrm{g}$ of the pMD-MoMLV gag-pol, the envelope encoding pMDGalV and transgene DNA in the pMMP-IRES-GFP vector were

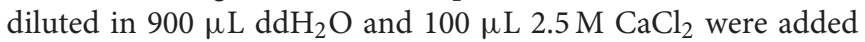
and incubated for $5 \mathrm{~min}$. Afterwards, $1 \mathrm{~mL} 2 \times \mathrm{HBSS}$ (Sigma Aldrich) was added and the mixture was spread on 293 cells at $10 \%$ confluency. On the next day, the mixture was removed and $10 \mathrm{~mL}$ fresh medium was added, and cells were cultured for 2 days two allow virus accumulation in the supernatant.

\section{Retroviral Transduction}

T-cells $\left(5 \times 10^{6} /\right.$ well $)$ were stimulated in 6 -well flat bottom plates with $5 \times 10^{6}$ anti-CD3/CD28 coated microbeads (Dynabeads, Invitrogen, Carlsbad, CA) and $300 \mathrm{U} / \mathrm{ml}$ IL-2 (Peprotech, London, UK) for $48 \mathrm{~h}$. Retroviral transduction was performed by addition of cell-free retroviral supernatant in the presence of $8 \mu \mathrm{g} / \mathrm{ml}$ polybrene (Sigma-Aldrich) followed by centrifugation at $900 \mathrm{~g}$ for $2 \mathrm{~h}$. Twenty-four hours after transduction, cells were transferred to fresh medium containing $100 \mathrm{U} / \mathrm{ml} \mathrm{IL-2}$ and cultured for another 3-7 days. Typical transduction efficiencies ranged between 30 and $70 \%$. Therefore, at the time point of the respective experiment, $\mathrm{GFP}^{+} \mathrm{T}$-cells were stringently isolated by FACS-sorting on a FACS Aria II flow cytometer (Becton Dickinson).

\section{Measurement of cAMP}

Jurkat cells were incubated for $16 \mathrm{~h}$ with medium containing $\left[{ }^{3} \mathrm{H}\right]$-adenine (1 $\mu \mathrm{Ci} / \mathrm{mL}$, PerkinElmer, Waltham, MA) to metabolically enrich the adenine nucleotide pool. Afterwards, cells were harvested, washed once with PBS and cells were resuspended in medium containing the phosphodiesterase inhibitor isobutylmethylxanthine $(100 \mu \mathrm{M}$; Sigma Aldrich). Subsequently, cells were stimulated with forskolin (30 $\mu \mathrm{M}$; sigma Aldrich) for $30 \mathrm{~min}$ to accumulate cAMP. After stimulation, cells were lysed in ice-cold $2.5 \%$ perchloric acid containing $0.1 \mathrm{mM}$ cAMP for $30 \mathrm{~min}$ at $4^{\circ} \mathrm{C}$ followed by neutralization of the lysis with $4.2 \mathrm{M} \mathrm{KOH}$ potassium hydroxide. ATP and cAMP were separated by sequential chromatography on columns containing Dowex 50-X4 (Sigma-Aldrich) and neutral alumina. Samples were then mixed with LSC-Universal Scintillation Cocktail (Roth, Karlsruhe, Germany) and the accumulated $\left[{ }^{3} \mathrm{H}\right] \mathrm{cAMP}$ and $\left[{ }^{3} \mathrm{H}\right]$ ATP was measured by on a liquid scintillation counter (PerkinElmer).

\section{Luciferase Assay}

Jurkat E6 cells expressing an IL-2::Luciferase reporter construct (44) were either pre-treated for $30 \mathrm{~min}$ with the PKA inhibitors Rp-8-Br-cAMPS (200 nM) or H89 (1 $\mu$ M; both Sigma Aldrich) or transduced with an empty control-vector or the human PDE4A cDNA. $2 \times 10^{6}$ cells were activated with PMA $\left(1 \times 10^{-7}\right.$ $\mathrm{M}$, Sigma Aldrich) and PHA $(12.5 \mu \mathrm{g} / \mathrm{mL}$; Thermo Scientific, Waltham, MA). After $6 \mathrm{~h}$, cells were lysed and luciferase activity was on a GloMax 96 well luminometer (Promega, Madison, WI).

\section{Proliferation Assay, Co-cultures, and T-cell Cultures}

$1 \times 10^{6}$ FACS-sorted PDE4A- or control vector-transduced $\mathrm{CD}^{+}{ }^{+}$and $\mathrm{CD}^{+}{ }^{+}$T-cells were activated with anti-CD3/antiCD28 coated microbeads (beads to cell ratio 1:2) in the presence or absence of the indicated concentrations of PGE2 or the A2A-R agonist CGS21680 (both Sigma Aldrich) in 96-well flat bottom plates in triplicates. After $72 \mathrm{~h}$, cells were pulsed with $1 \mathrm{mCi}$ methyl- $\left[{ }^{3} \mathrm{H}\right]$ thymidine/well for an additional $18 \mathrm{~h}$, and thymidine incorporation was measured on a PerkinElmer scintillation counter (PerkinElmer, Waltham, MA), as described (42).

For co-cultures, $5 \times 10^{5}$ FACS-sorted PDE4A- or control vector-transduced T-cells were activated with anti-CD3/antiCD28 coated microbeads (beads to cell ratio 1:2) in the presence or absence of FOXP3-transgenic CD4 ${ }^{+}$T-cells or FACSsorted $\mathrm{CD} 4{ }^{+} \mathrm{CD} 25^{+} \mathrm{CD} 127^{\text {low }}$ thymic-derived regulatory T-cells at the indicated ratios. Proliferation was measured by thymidine incorporation as above. Values were corrected for proliferation of Treg in single culture.

In some experiments, transduced T-cells were FACS sorted for $\mathrm{GFP}^{+} \mathrm{CD}^{+}$or $\mathrm{GFP}^{+} \mathrm{CD}^{+}$cells and were activated with anti-CD3/anti-CD28 coated microbeads (beads to cell ratio 1:2) plus recombinant human IL-2 $(10 \mathrm{U} / \mathrm{mL})$. After seven and 14 days, cells were harvested, washed once in PBS and re-stimulated as above.

\section{Cytokine Measurements}

$1 \times 10^{6}$ FACS-sorted PDE4A- or control vectortransduced $\mathrm{CD}^{+}$and $\mathrm{CD}^{+}{ }^{+}$-cells were activated with 
anti-CD3/anti-CD28 coated microbeads (beads to cell ratio $1: 2)$ in the presence or absence of the indicated concentrations of PGE2. After 24 and $72 \mathrm{~h}$ supernatants were harvested and levels of IL-2 (24h supernatants) and IFN- $\gamma$ and TNF- $\alpha$ (72 h supernatants) were measured using specific ELISA (eBioscience) according to the manufacturers' recommendations.

\section{Immunoblotting}

$1 \times 10^{6}$ FACS-sorted PDE4A- or control vector-transduced total T-cells were either left unstimulated or activated in the absence or presence of $200 \mathrm{nM}$ PGE2 for $24 \mathrm{~h}$ using $5 \times 10^{5}$ antiCD3/anti-CD28 coated microbeads. Cells were then harvested and lysed in RIPA buffer supplemented with protease inhibitors (Sigma). Cellular debris was removed by centrifugation at 25,000 $\times \mathrm{g}$ at $4^{\circ} \mathrm{C}$ for $15 \mathrm{~min}$. Samples were normalized according to their protein content and were resolved by SDS-PAGE on 4$12 \%$ gradient gels under reducing conditions (Life Technologies, Paisley, UK) followed by transfer onto PVDF membranes (GE Healthcare). Samples were then subjected to immunoblotting using the following antibodies: rabbit anti-S6 (clone 5G10), rabbit anti-p38 (clone D13E1), rabbit anti-ERK (polyclonal) and rabbit anti-Actin (clone D18C11; all New England Biolabs, Ipswich, MA). After incubation with a secondary anti-rabbit horse radish peroxidase-conjugated antibody, binding was visualized using the SuperSignal West Pico Chemiluminescent Substrate (Thermo Scientific, Rockford, IL).

\section{Flow Cytometry}

All flow cytometry and FACS sorting experiments were conducted in accordance with the current guidelines (45). All analyses were performed on a FACS Canto II flow cytometer (Becton Dickinson) and analyzed using FlowJo software.

For intracellular measurement of PDE4A and cytokine expression, the Fix and Perm buffer set (An der Grub, Kaumberg, Austria) was used according to the manufacturers' recommendations. Cells were stained with a primary antihuman PDE4A antibody (clone 6B6; Abcam, Cambridge, UK) followed by staining with a PE-conjugated goat anti-mouse IgG antibody (Jackson Immuno Research; West Grove, PA). For measurement of intracellular cytokines, FACS-sorted Tcells were stimulated for $24 \mathrm{~h}$ (IL-2) or $48 \mathrm{~h}$ (IFN- $\gamma$ and TNF$\alpha$ ). During the last $6 \mathrm{~h}$ of culture Golgi-Stop reagent (Becton Dickinson, Palo Alto, CA) was added at a dilution of 1:1,500. Afterwards cells were harvested, fixed and permeabilized and stained with the respective antibodies against human IL-2 (PE or APC-conjugated; clone MQ1-17H12), IFN- $\gamma$ (APCconjugated; clone 4S.B3) and TNF- $\alpha$ (PerCP-Cy5.5 conjugated; clone MAb11; all eBioscience). To determine phosphorylation of intracellular signaling proteins, FACS-sorted T-cells were activated for $24 \mathrm{~h}$ and processed as described previously. Cells were harvested and fixated in Fixation Buffer I (BD Phosflow, $\mathrm{BD}$ Biosciences) at $37^{\circ} \mathrm{C}$ for $10 \mathrm{~min}$. After washing in PBS $+0.5 \% \mathrm{BSA}+0.05 \% \mathrm{NaN}_{3}$, cells were re-suspended in prechilled $\left(-20^{\circ} \mathrm{C}\right)$ Permeabilization Buffer III (BD Phosflow) and incubated on ice for $30 \mathrm{~min}$. Afterwards, cells were washed twice in PBS $+0.5 \% \mathrm{BSA}+0.05 \% \mathrm{NaN}_{3}$ and stained with the respective antibodies (anti-phospho-S6RP S240; Alexa Fluor 647 conjugated; clone N4-41; anti-phospho-ERK T202/Y204; Pacific Blue conjugated; clone $20 \mathrm{~A}$ and anti-phospho-p38 T180/Y182; PE conjugated; clone 36/p38; BD Phosflow) or isotype-matched control antibodies for $60 \mathrm{~min}$. For measurement of $\mathrm{CD}^{+}{ }^{+} \mathrm{T}$ cell degranulation, control-vector or PDE4A-transduced $\mathrm{CD}^{+}$ T-cells were FACS-sorted 3 days after transduction and cocultured with BW target cells expressing a membrane-bound OKT3::scFv antibody (BW 3/2) labeled with $5 \mu \mathrm{M}$ eF450 CPD (eBioscience). Co-culture was performed in the presence or absence of $200 \mathrm{nM}$ PGE2. Two hours after the start of coculture, Golgi-Stop reagent (Becton Dickinson, Palo Alto, CA) was added at a dilution of 1:1,500. After a total co-culture of $6 \mathrm{~h}$, cells were harvested, surface stained with an eFluor670conjugated anti-human CD107a antibody (clone eBioA4H3; eBioscience) and subsequently fixed and permeabilized as in the intracellular cytokine protocol and stained for intracellular expression of granzyme B (PE-conjugated; clone GB11; Becton Dickinson). Afterwards, CD107a and granzyme B expression on $\mathrm{GFP}^{+} /$eFluor $450^{-}$T-cells were measured. For determination of surface expression of CD69 (eFluor450-conjugated; clone FN50), CD73 (eFluor450-conjugated; clone AD2), CD94 (APCconjugated, clone HP-3D9), CD244 (PE-conjugated, clone C17) PD-1 (PerCP-eFluor 710 conjuagted, clone J105), and TIM3 (PE-conjugated; Rat IgG2a Clone \#344823; R\&D Systems, Minneapolis, MN) FACS-sorted T-cells were harvested from the respective cultures and washed twice in PBS $+5 \%$ BSA $+0.05 \%$ $\mathrm{NaN}_{3}$ and stained for $30 \mathrm{~min}$ at $4{ }^{\circ} \mathrm{C}$, followed by another wash step in $\mathrm{PBS}+5 \% \mathrm{BSA}+0.05 \% \mathrm{NaN}_{3}$.

\section{Cytotoxicity Assays}

Purified human $\mathrm{CD}^{+}$T-cells were transduced with either the PDE4A cDNA or an empty control-vector. Three days after transduction, $\mathrm{GFP}^{+} \mathrm{T}$-cells were isolated by FACS-sorting and $\mathrm{T}$ cells were co-cultured with $5 \times 10^{4} \mathrm{BW}$ target cells expressing a membrane-bound OKT3::scFv antibody labeled with $5 \mu \mathrm{M}$ eF450 CPD (eBioscience) at the indicated ratios. After $6 \mathrm{~h}$, cells were harvested, washed and $5 \times 10^{4}$ cell-counting beads and propidium iodide (final $100 \mathrm{ng} / \mathrm{mL}$ ) were added. Viable BW target cells were quantified by flow cytometry by exclusion of $\mathrm{GFP}^{+} \mathrm{T}$-cells and gating eF450 $/ \mathrm{PI}^{-}$cells. Single culture of BW cells without transgenic T-cells served as control. Specific lysis was calculated according to the formula:

Number of viable BW cells (co-culture) per $10^{5}$ counting beads/number of viable BW cells (control culture) per $10^{5}$ counting beads.

\section{Statistical Analyses}

For multiple group comparisons, one-way ANOVA followed by Bonferroni correction was performed using GraphPad Prism version 5.0 for Windows (GraphPad Software, San Diego CA, USA). Two-group comparisons were performed using the Student's $t$-test. Data represent mean values $+\mathrm{SD}$. Statistically significant values are denoted as follows: ${ }^{*} P<0.05$; ${ }^{* *} P<0.01$; and ${ }^{* * *} P<0.001$. 
A

Rp-8-Br-cAMPS

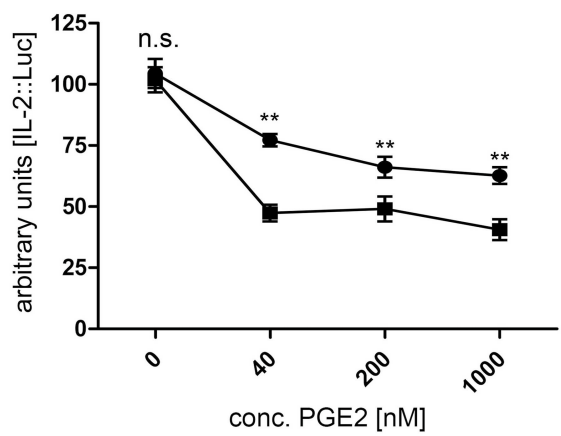

B

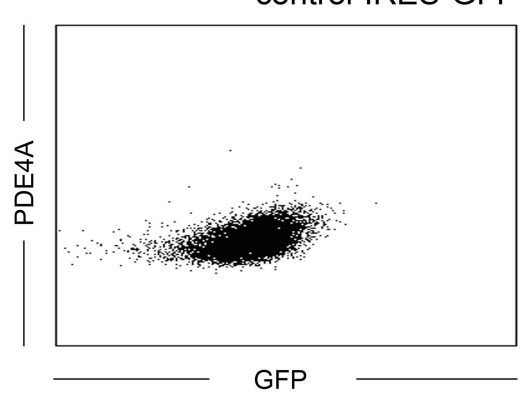

C

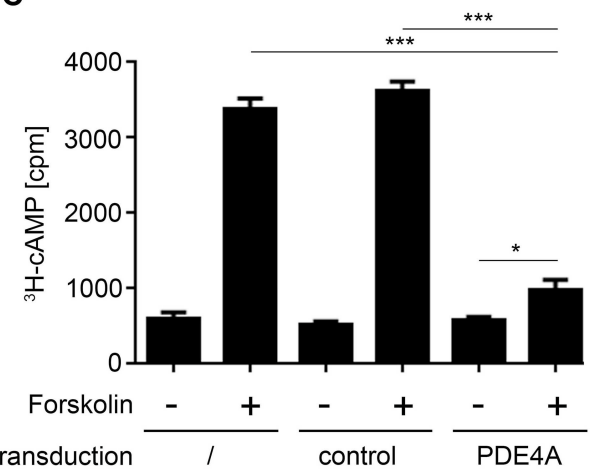

H89

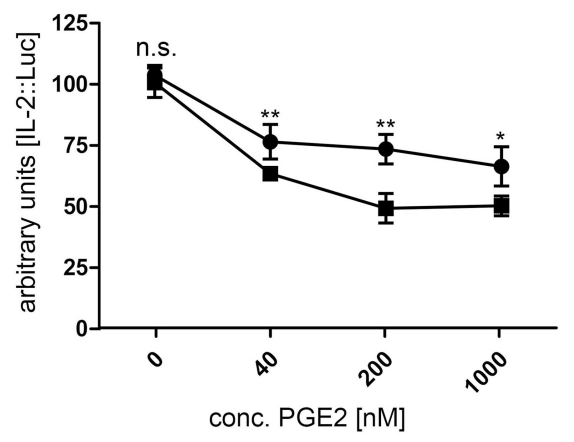

PDE4A-IRES-GFP

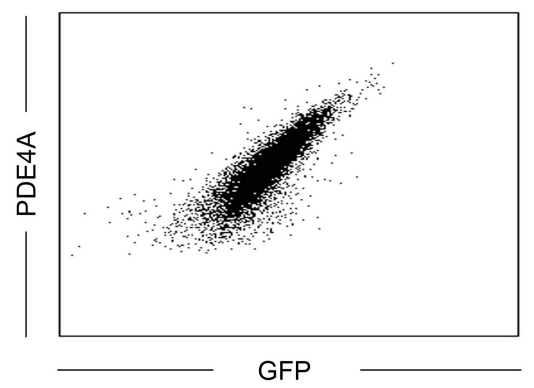

D

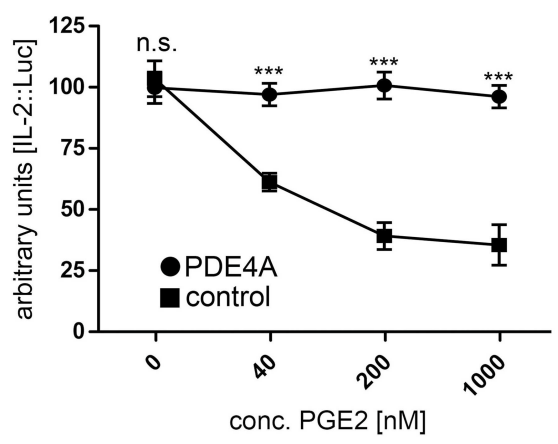

FIGURE 1 | Overexpression of PDE4A counteracts cAMP mediated immunosuppression in Jurkat T-cells. (A) Jurkat IL-2P::Luc T-cells were pre-incubated with the PKA inhibitors Rp-8-Br-cAMPS (200 nM; left panel) or H89 (1,000 nM; right panel) and activated with PHA/PMA in the presence of the indicated concentrations of PGE2. After $6 \mathrm{~h}$, cells were lysed and Luciferase activity was measured. Mean values \pm SD from triplicate cultures from one representative experiment $(n=4)$ are shown. Squares: untreated cells, circles: cells treated with the respective inhibitor. (B) Jurkat T-cells were retrovirally transduced with either an empty control vector (left histogram) or the pMMP-PDE4A-IRES-GFP vector (right histogram). Following fixation and permeabilization of the cells, intracellular expression of PDE4A was measured using a mouse anti human PDE4A antibody followed by a PE-conjugated goat anti-mouse antibody. Histograms depict one representative experiment out of five. (C) Wildtype, control-vector transduced and PDE4A transduced Jurkat T-cells were pulsed with ${ }^{3}[\mathrm{H}]$-adenosine overnight and adenylate cyclase activity was induced by addition of $30 \mu \mathrm{M}$ Forskolin. After $30 \mathrm{~min}$, cells were lysed and the cAMP fraction was isolated by sequential chromatography and radioactivity was quantified on a scintillation counter. Mean values + SD from six individual experiments are depicted. (D) Control vector transduced (circles) or PDE4A transduced Jurkat IL-2P::Luc T-cells (squares) were activated with PHAPMA in the presence of the indicated concentrations of PGE2. After $6 \mathrm{~h}$ cells were lysed and Luciferase activity was measured. Mean values \pm SD from triplicate cultures from one representative experiment $(n=4)$ are shown. ${ }^{*} p<0.05 ;{ }^{* \star} p<0.01 ;{ }^{* \star *} p<0.001$.

\section{RESULTS}

\section{Pharmacological Inhibition of PKA Partially Restores IL-2 Production in Jurkat T-cells Under Suppression by PGE2}

The PKA is one of the crucial signaling hubs for cAMP mediated immunosuppression. Thus, we first aimed to restore
T-cell reactivity in the presence of PGE2 by use of the two well-defined PKA inhibitors Rp-8-Br-cAMPS and H89. In line with previous reports (46), we found that treatment of Jurkat T-cells with these inhibitors partially restored IL2 promoter activity upon activation in the presence of suppressive concentrations of PGE2 (Figure 1A). This effect was especially pronounced at lower concentrations of PGE2 
but a significant increase in IL-2 promoter activity was also found at highly suppressive concentrations $(1,000 \mathrm{nM}$ PGE2; $n=4 ; p<0.01$ for Rp-8-Br-cAMPS and $p<0.05$ for $\mathrm{H} 89$ compared to mock-treated cells). However, neither inhibitor could completely abrogate the suppressive effects of PGE2.

\section{Ectopically Expressed PDE4A in T-cells Efficiently Degrades cAMP Following Exposure to PGE2}

Given that cAMP also triggers PKA-independent signaling pathways, we aimed to fully abrogate the suppressive effects of cAMP by ectopic overexpression of cAMP degrading phosphodiesterases. The human PDE4A cDNA was cloned into the retroviral PMMP-IRES-GFP vector, which guarantees highlevel overexpression with a strong correlation to expression of the GFP marker gene. Upon retroviral transduction into Jurkat T-cells, followed by isolation of $\mathrm{GFP}^{+}$cells by FACS-sorting, we found a robust expression of PDE4A, which was not present in control-vector transduced Jurkat cells (Figure 1B). To confirm functionality of the PDE4A transgene, we measured cAMP levels in untransduced, control-vector transduced and PDE4Atransduced Jurkat T-cell in response to the adenylate cyclase activator forskolin. As expected, a highly significant increase in cAMP levels could be observed in untransduced and controlvector transduced Jurkat T-cells, while PDE4A-expressing Jurkat cells showed only a slight increase in cAMP (Figure 1C). To further assess the functional impact of PDE4A overexpression, IL-2 promoter activity was measured in Jurkat T-cells following activation in the presence of PGE2. As above, activation of control-vector transduced Jurkat T-cells was strongly suppressed by PGE2 in a dose dependent fashion (Figure 1D). In contrast, PDE4A-overexpression led to a nearly complete restoration of activation. Even at high concentrations of PGE2 (200nM and $1,000 \mathrm{nM}), \mathrm{IL}-2$ promoter activity reached $95.1 \pm 5.1$ and $93.3 \pm 6.5 \%$ of promoter activity of the control $(p=0.57$ and 0.48 , respectively; $n=4$; Figure 1D). Importantly, PDE4A and control-vector transduced Jurkat T-cells showed similar IL2 promoter activity when activated in the absence of PGE2, indicating that PDE4A overexpression does not interfere with T-cell activation per se.

\section{Activity of Ectopically Expressed PDE4A Counteracts the Suppressive Effects of PGE2 and A2A-R Agonists on T-cell Activation}

In a next step, we assessed the effects of PDE4 overexpression on the activation of human peripheral blood T-cells. As early activation readouts we measured phosphorylation of the mTOR downstream target S6RP as well as the MAP kinases p38 and ERK following activation with agonistic anti-CD3/anti-CD28 antibodies in the absence or presence of PGE2. In FACS-sorted, control-vector transduced T-cells a significant downregulation of phosphorylation for all three molecules was found in the presence of PGE2 ( $p<0.001$, respectively; $n=4$; Figure $2 \mathrm{~A})$. In contrast, FACS-sorted PDE4A-transduced T-cells showed equal up-regulation of ERK-, p38- and S6RP-phosphorylation in the absence and presence of PGE2 (Figure 2A). Under all conditions, total protein levels were unchanged (Supplementary Figure 1). Similarly, up-regulation of the early activation surface marker CD69 was strongly suppressed by PGE2 on control-vector transduced $\mathrm{CD}^{+}{ }^{+}$and $\mathrm{CD} 8^{+}$T-cells, while PDE4A-transduced T-cells showed a significant upregulation of CD69, especially in $\mathrm{CD}^{+}$T-cells, in the presence of PGE2 (Figures 2B,C). In further experiments, proliferation of FACS-sorted controlvector transduced and $\mathrm{PDE} 4 \mathrm{~A}$-transduced $\mathrm{CD} 4^{+}$and $\mathrm{CD} 8^{+}$ T-cells in the absence or presence of PGE2 or the A2A-R agonist CGS21680 was measured. Similar to the observations in Jurkat T-cells, overexpression of PDE4A in $\mathrm{CD}^{+}$and $\mathrm{CD}^{+}$T-cells did not alter their activation compared to their control-transduced counterparts under non-suppressive conditions $\left(p=0.751\right.$ for $\mathrm{CD}^{+}$and $p=0.863$ for CD8; $n=$ 7; Figures 3A,B). A dose-dependent inhibition of proliferation by PGE2 was observed for control-transduced $\mathrm{CD}^{+}$as well as $\mathrm{CD}^{+}{ }^{+}$T-cells following anti-CD3/anti-CD28 mediated activation. A significant decrease in proliferation was already observed at $50 \mathrm{nM}$ PGE2 $(p<0.001 ; n=7)$ and proliferation was suppressed by $62.7 \pm 8.6 \%$ for $\mathrm{CD}^{+}$and $73.5 \pm$ $11.6 \%$ for $\mathrm{CD}^{+}$T-cells in the presence of $200 \mathrm{nM}$ PGE2 $(p<0.001 ; n=7)$. In contrast, PDE4A-transgenic $\mathrm{CD}^{+}$ as well as $\mathrm{CD}^{+}$T-cells were again completely resistant to the effects of PGE2, showing nearly equal proliferation levels in the presence as in the absence of PGE2 (Figure 3A). Similarly, culture of control-vector transduced T-cells in the presence of the A2A-R agonist CGS21680 strongly suppressed proliferation of $\mathrm{CD}^{+}$as well as $\mathrm{CD}^{+}$T-cells (reduction of proliferation by $63.1 \pm 7.2 \%$ for $\mathrm{CD}^{+}$and $57.7 \pm$ $7.2 \%$ for $\mathrm{CD}^{+} ; p<0.001$, respectively, $n=5$ ). As above, overexpression of PDE4A also effectively abrogated suppression by the A2A-R agonist CGS21680 even under highly suppressive conditions (Figure 3B).

In order to further analyze T-cell function under these conditions, cytokine secretion levels from the corresponding cell culture supernatants were measured. In accordance with the proliferation experiments, control-vector transduced $\mathrm{CD}^{+}$and $\mathrm{CD}^{+}$T-cells showed a pronounced and dosedependent reduction of the secretion of the effector cytokines IL-2, IFN- $\gamma$ and TNF- $\alpha$ in the presence of PGE2. Again, the transduction of PDE4A completely abrogated the suppressive effects of PGE2 in these assays (Figure 3C). No significant difference in the cytokine secretion between PDE4A-transgenic T-cells and control-vector transduced T-cells was observed in the absence of PGE2 (Figure 3C). These observations were also confirmed by intracellular FACS analyses with control-vector and PDE4A-transduced $\mathrm{CD}^{+}{ }^{+}$and $\mathrm{CD}^{+}{ }^{+} \mathrm{T}$-cells (Supplementary Figure 2). In these experiments, we also found that PGE2 strongly reduced the number of polyfunctional IFN $-\gamma^{+} / \mathrm{TNF}-\alpha^{+} \mathrm{CD}^{+}$Tcells. As above, FACS-sorted PDE4A-transgenic cells were fully resistant to suppression by PGE2 also in this read-out (Supplementary Figure 3). 
A

ERK (pT202/pY204)

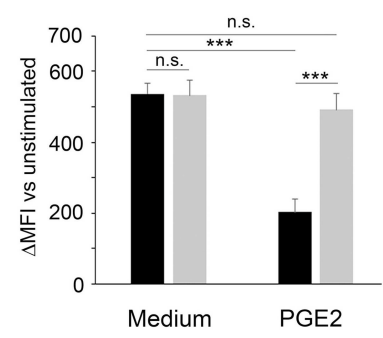

B

\section{$\mathrm{CD}^{+}$}
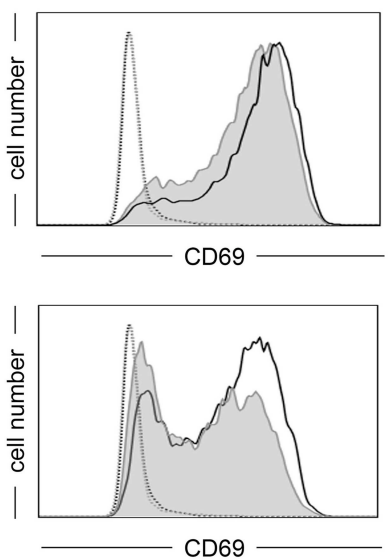

C

CD4 $^{+}$

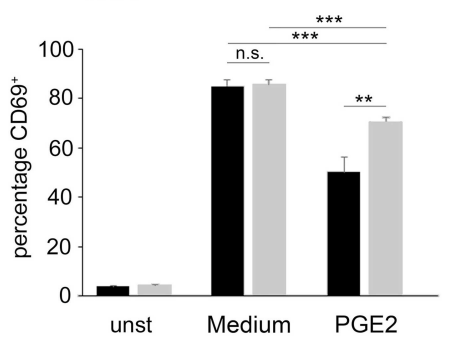

p38 (pT180/pY182)

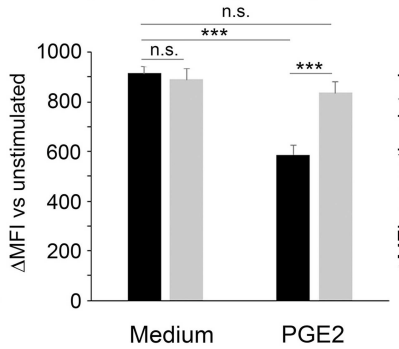

CD8 ${ }^{+}$
S6RP (pS240)

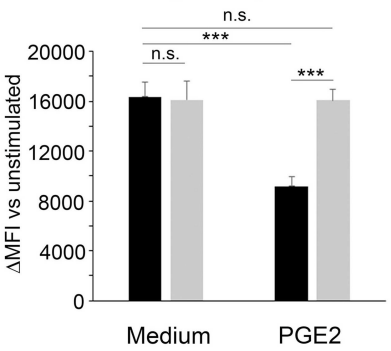

Medium

PGE2

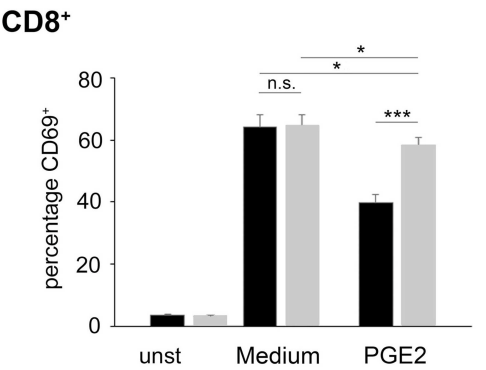

FIGURE 2 | Overexpression of PDE4A restores early activation parameters in peripheral blood T-cells under suppression by PGE2. (A) FACS-sorted control-vector transduced (black bars) or PDE4A transduced (gray bars) human peripheral blood T-cells were activated using anti-CD3/anti-CD28 antibodies in the absence (Medium) or presence of $200 \mathrm{nM}$ PGE2. After $24 \mathrm{~h}$, phosphorylation of the indicated signaling proteins was measured by intracellular flow cytometry. Data show the increase in mean fluorescence intensity to the respective unstimulated cells. Mean values + SD from four independent experiments are depicted. (B) FACS-sorted control-vector transduced (gray filled histograms) or PDE4A (black line) transduced CD4+ (left panels) or CD8 ${ }^{+}$(right panels) human T-cells were either left unstimulated (dotted line and fine gray line) or were activated for $24 \mathrm{~h}$ in the absence (upper panels) or presence (lower panels) of $200 \mathrm{nM}$ PGE2. After 24 h, CD69 expression was measured by flow cytometry. One representative experiment $(n=4)$ is depicted. (C) The percentage of CD69+ control-vector (black bars) or PDE4A(gray bars) transduced $\mathrm{CD}^{+}$(left panels) and $\mathrm{CD}^{+}$(right panels) T-cells either unstimulated or activated for $24 \mathrm{~h}$ in the absence (Medium) or presence of $200 \mathrm{nM}$ PGE2 is depicted. Mean values + SD from four independent experiments are shown. n.s., not significant; ${ }^{*} p<0.05 ;{ }^{* *} p<0.01 ;{ }^{* * *} p<0.001$.

\section{PDE4A Overexpression Restores the Cytotoxic Function of CD8 ${ }^{+}$T-cells Under Suppression by PGE2}

One key anti-tumor function of the adaptive immune system is the removal of malignant cells by cytotoxic $\mathrm{CD}^{+} \mathrm{T}$-cells. Accordingly, we tested the impact of PDE4A-overexpression on the cytotoxic function of $\mathrm{CD}^{+}$T-cells. As model target cells we used the mouse thymoma BW5147 cell line which was modified to stably express a membrane-bound OKT3 single chain fragment variable (mb-OKT3scFv) as surrogate T-cell ligand (further on referred to as BW). Following co-incubation of FACS-sorted control-vector transduced and PDE4A-transduced $\mathrm{CD}^{+}{ }^{+} \mathrm{T}$-cells with the BW target cells, a strong up-regulation of the degranulation marker CD107a was detected (Figures 4A,C). 

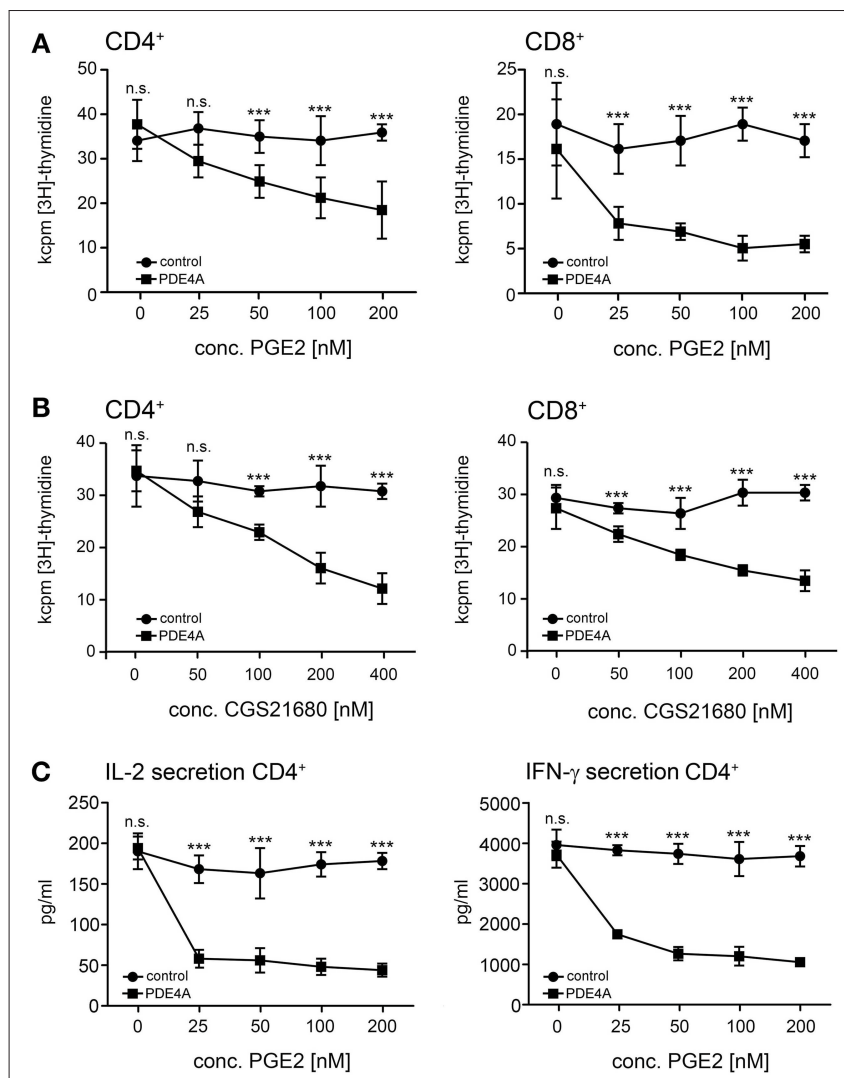

TNF- $\alpha$ secretion $\mathrm{CD}^{+}$

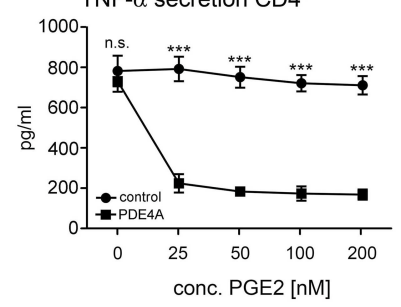

IL-2 secretion $\mathrm{CD}^{+}$
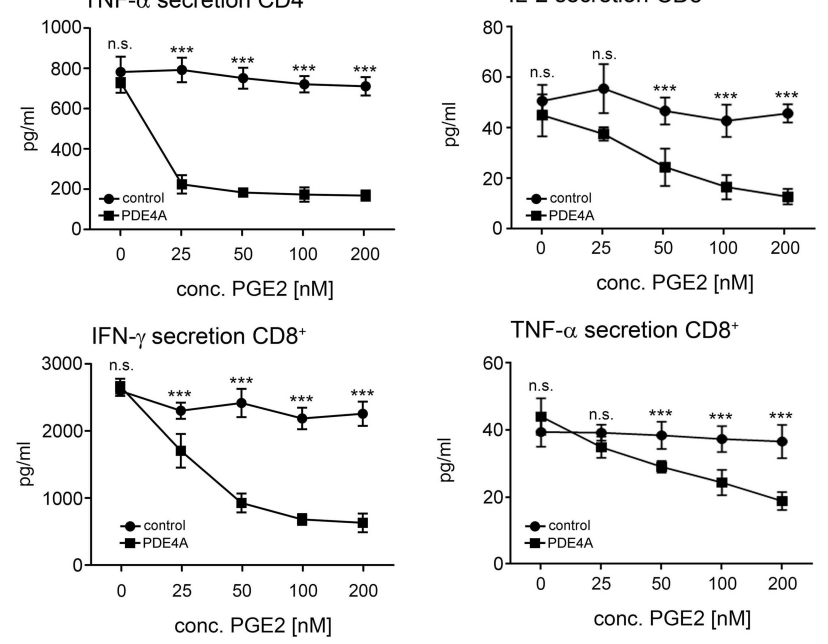

This effect was equally pronounced in both cell-types (mean fluorescence intensity increase $858 \pm 72$ for control-vector and $785 \pm 107$ for PDE4A; $p=0.15 ; n=5$ ). In the presence of $200 \mathrm{nM}$ PGE2, CD107a up-regulation was nearly abrogated in control-vector transduced T-cells. Under these conditions, PDE4A-transgenic cells were able to mount a robust upregulation of $\mathrm{CD} 107 \mathrm{a}$, which amounted to $64.1 \pm 9.5 \%$ of the level in the absence of PGE2 $(p<0.01$; Figures 4A,C). The effector molecule granzyme $\mathrm{B}(\mathrm{GrzB})$ is essential for the cytotoxic function of $\mathrm{CD} 8^{+}$T-cells. Accordingly, we also combined measurement of the surface levels of the degranulation marker CD107a with intracellular GrzB expression. The percentage of $\mathrm{CD} 107 \mathrm{a}^{+} / \mathrm{GrzB}^{+}$cells was strongly down-regulated by PGE 2 in control-vector transduced cells (10.3 \pm 1.5 vs. $0.4 \pm 0.2 \%$; $p<$ $0.01 ; n=4)$. As above, PDE4A-transduced cells showed similar levels of $\mathrm{CD} 107 \mathrm{a}^{+} / \mathrm{GrzB}^{+}$cells in comparison to control-vector transduced cells under non-suppressive conditions and were able to strongly induce CD107a ${ }^{+} / \mathrm{GrzB}^{+}$cells in the presence of PGE2 $(9.9 \pm 1.1$ vs. $7.4 \pm 0.8 \%$; $p<0.05 ; n=4$; Figures $4 \mathrm{~B}, \mathbf{C})$. Finally, we evaluated the lytic function of PDE4A-transduced $\mathrm{CD}^{+}$T-cells in a FACS-based cytotoxicity assay. We found that both control-vector transduced and PDE4A-transduced $\mathrm{CD} 8^{+} \mathrm{T}$ cells were able to efficiently lyse BW cells in a dose-dependent manner. In the absence of PGE2, no significant difference in the cytotoxic capacity between the two cell types was observed (Figure 4D). Again, upon pre-incubation with $200 \mathrm{nM}$ PGE2, a significant down-regulation in cytotoxicity was observed in control-vector transduced $\mathrm{CD} 8^{+} \mathrm{T}$-cells $(p<0.001$ at all effector: target ratios; $n=4)$. In contrast, PDE4A-transduced T-cells were again fully resistant to the suppressive effects of PGE2 and showed a similar cytotoxic potency in the presence and absence of PGE2 (Figure 4D and Supplementary Figure 4).

\section{PDE4A-transgenic T-cells Are Partially Resistant to Suppression by Regulatory T-cells}

An important mechanism of Treg-mediated immunosuppression is conferred by an increase of cAMP in effector T-cells. Consequently, we hypothesized that overexpression of PDE4A in T-cells may also generate resistance to suppression by Treg. In a first proof of principle experiment, we co-cultivated FACSsorted control-vector transduced or PDE4A-transduced T-cells with FOXP3-transgenic regulatory T-cells. As expected a robust and dose-dependent inhibition of control-vector transduced effector T-cells was observed which amounted to $87.5 \pm 9.8 \%$ at a Treg: Teff ratio of 1:1. In contrast to the experiments described above, PDE4A-overexpressing T-cells showed a similar reduction in proliferation under these conditions $(89.6 \pm 7.3 \%$; $p=0.749$ compared to control-vector transduced T-cells, $n=3$; Figure 5A). However, PDE4A-overexpression resulted in enhanced activation at lower Treg to Teff ratios. This effect could already be observed at a Teff: Treg ratio of 1:2 (78 \pm 6.4 vs. $62.4 \pm 4.0 \%$ reduction of proliferation; $p<0.01$ ) and was especially pronounced at ratios of 1:4 and 1:8 (56.3 \pm 4.2 vs. $24.1 \pm 5.7$ and $37.5 \pm 4.9$ vs. $8.7 \pm 3 \%$ reduction of proliferation, respectively; $p<0.001$ and $p<0.01$; Figure 5A). In 


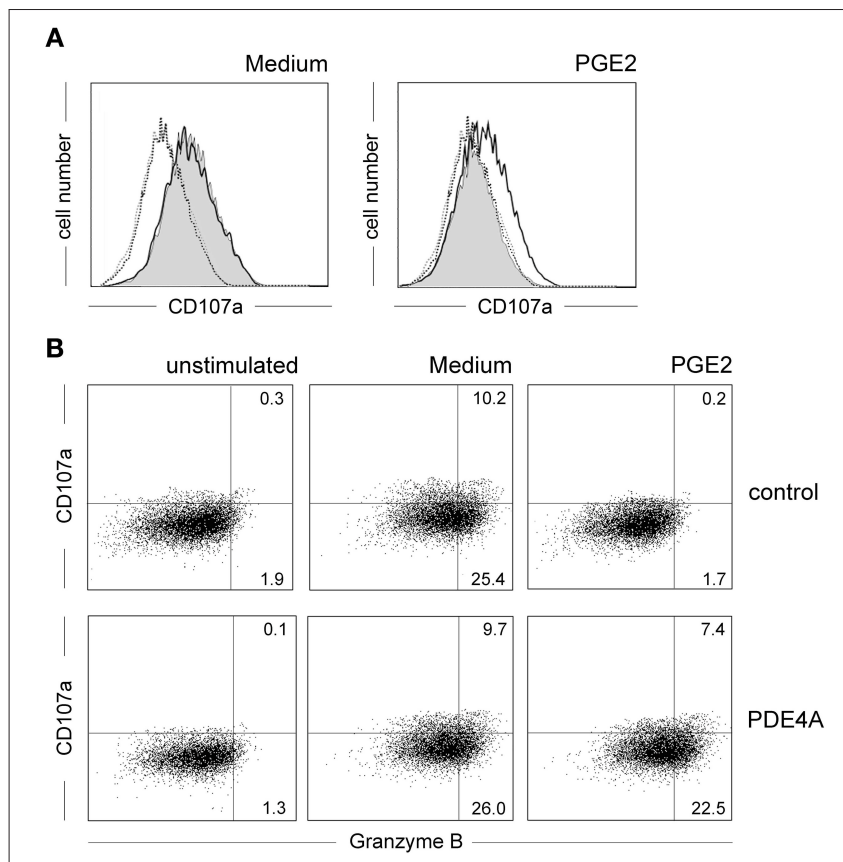

C

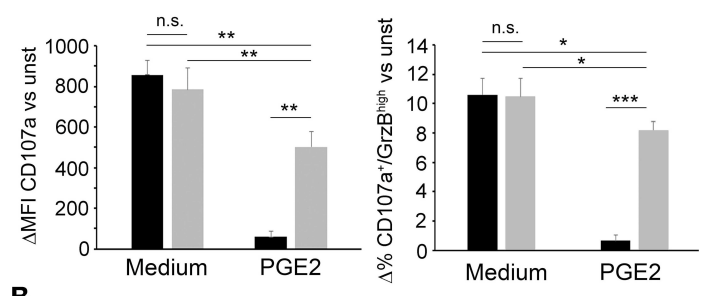

B

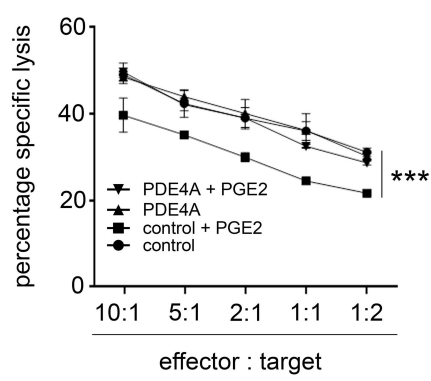

FIGURE 4 | Overexpression of PDE4A restores cytotoxic function of $\mathrm{CD}^{+}$ T-cells in the presence of PGE2. (A) FACS-sorted control-vector transduced (gray filled histograms) or PDE4A transduced (black line) human $\mathrm{CD} 8^{+} \mathrm{T}$-cells were co-cultured with BW cells expressing a membrane-bound OKT3::scFv at a 10:1 ratio in the absence (Medium) or presence of $200 \mathrm{nM}$ PGE2. After $6 \mathrm{~h}$, expression of CD107a/LAMP-1 was measured by flow cytometry. Dotted black line: unstimulated control; dotted gray line: unstimulated PDE4A. One representative experiment is depicted $(n=6)$. (B) Co-staining of surface expression of CD107a and intracellular expression of Granzyme B on control-vector transduced (upper panel) and PDE4A-transduced (lower panel) cells under the same conditions as in (A). One representative experiment is depicted $(n=4)$. (C) Cumulative data are depicted as difference to unstimulated cells at the indicated conditions. black bars: control-vector transduced; gray bars: PDE4A transduced; mean values + SD are shown. (D) Specific lysis of BW target cells by control-vector transduced or PDE4A transduced human $\mathrm{CD}^{+}{ }^{+} \mathrm{T}$-cells in the absence or presence of $200 \mathrm{nM}$ PGE2 at the indicated effector: target cell ratios. Mean values $+\mathrm{SD}$ from six independent experiments are shown. n.s., not significant; ${ }^{*} p<0.05$;

${ }^{* \star} p<0.01 ;{ }^{* \star *} p<0.001$.

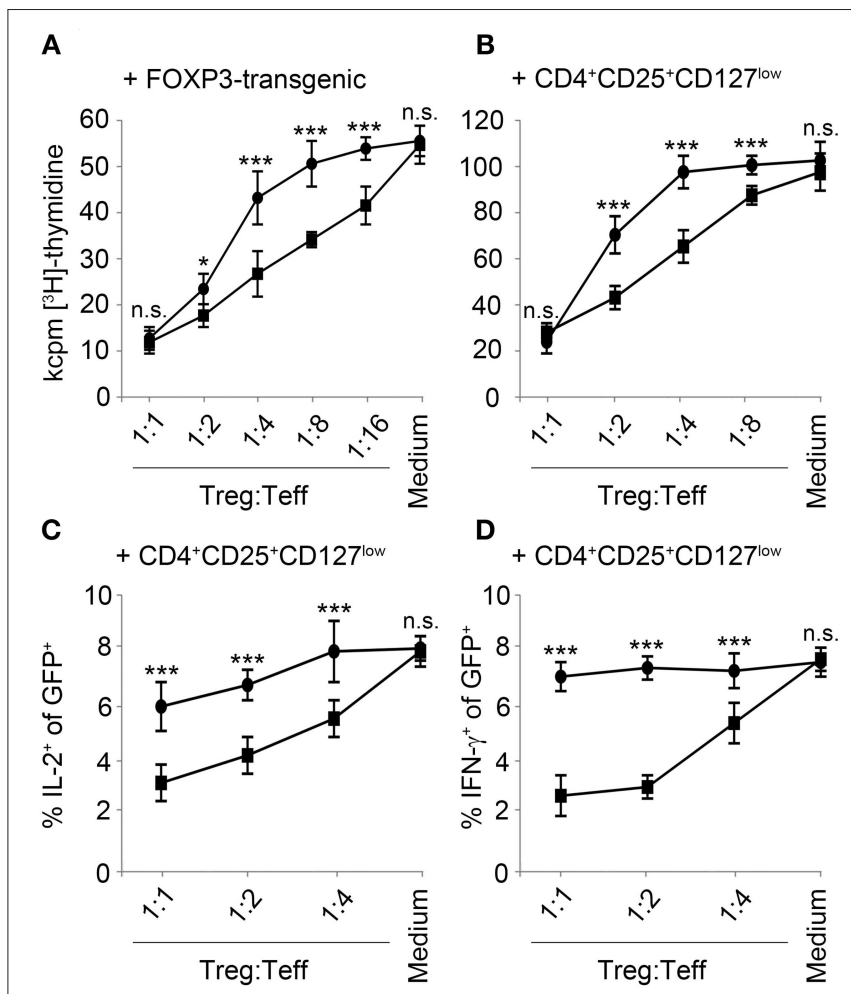

FIGURE 5 | Overexpression of PDE4A partially restores T-cell activation under suppression by regulatory T-cells. Control-vector transduced (squares) or PDE4A transduced (circles) human T-cells were co-cultured with FOXP3 transduced $\mathbf{( A )}$ or peripheral blood tTreg $\mathbf{( B )}$ at the indicated ratios. After $72 \mathrm{~h}$, cells were labeled with $\left[{ }^{3} \mathrm{H}\right]$-thymidine for another $18 \mathrm{~h}$ and thymidine incorporation was measured. Mean values \pm SD from triplicate cultures from one representative donor $(n=4)$ are depicted. $(\mathbf{C}, \mathbf{D})$ Control-vector transduced (squares) or PDE4A transduced (circles) human T-cells were co-cultured with peripheral blood tTreg for $24 \mathrm{~h}$ and expression of IL-2 (C) and IFN- $\gamma$ (D) was measured in the GFP ${ }^{+}$effector T-cells by intracellular flow cytometry. Mean values \pm SD from three independent experiments are depicted. n.s., not significant; ${ }^{\star} p<0.05$; ${ }^{\star \star \star} p<0.001$.

accordance, a similar pattern was observed when control-vector transduced and PDE4A-transduced T-cells were co-cultured with peripheral blood $\mathrm{CD} 4{ }^{+} \mathrm{CD} 25^{+} \mathrm{CD} 127^{\text {low }}$ tTreg from the same donor (Figure 5B). To further assess the impact of PDE4Atransduction in co-cultures with regulatory $\mathrm{T}$-cells, we also measured cytokine production in the $\mathrm{GFP}^{+}$transgenic effector T-cells using intracellular flow cytometry. In contrast to the observations from the proliferation assays, intracellular levels of IL- 2 and IFN- $\gamma$ were less affected in PDE4A-transgenic Tcells than in control-vector transduced T-cells (Figure 5C). At a Treg: Teff ratio of $1: 1$, the percentage of IL-2 positive cells was reduced from $8.7 \pm 0.3$ to $3.9 \pm 0.3 \%(p<0.001, n=$ 3 , Figure 5C) in control-vector transduced T-cells, while only a slight reduction was observed in PDE4A-transduced T-cells (8.6 \pm 0.6 to $6.2 \pm 0.4 \% ; p<0.01)$. At lower Treg: Teff ratios IL2 production in PDE4A-transgenic T-cells recovered to levels under no suppression, while the percentage of IL-2 positive cells was still strongly reduced in control-vector transduced Tcells $(4.8 \pm 0.3$ and $6.6 \pm 0.5$ vs. $6.8 \pm 0.2 \%$ and $7.8 \pm 0.6 \%$ 
at 1:2 and 1:4 tTreg: Teff ratios; $p<0.001$ and $p<0.01$; $n=3)$. Similarly, IFN- $\gamma$ levels in control-vector transduced T-cells were strongly suppressed by PGE2 from $7.0 \pm 0.4$ to $2.7 \pm 0.5 \%$ at $1: 1$ tTreg:Teff ratios $(p<0.001 ; n=3)$. In PDE4A-transduced T-cells only a slight reduction of IFN- $\gamma$ was observed under these conditions $(7.1 \pm 0.3$ to $6.1 \pm 0.7 \%$, $p=0.27 ; n=3$ ) which was not statistically significant. Along those lines IFN- $\gamma$ production in PDE4A-transduced T-cells was completely restored at lower tTreg:Teff ratios (Figure 5C and Supplementary Figure 5).

\section{PDE4A Counteracts Upregulation of Inhibitory Surface Molecules and Does Not Affect Exhaustion Upon in vitro Culture}

Previous studies have established that PGE2 does not only directly suppress T-cell activation, but also leads to the upregulation of inhibitory molecules which could further potentiate an immunosuppressive environment (47). In line with these findings, culture of FACS-sorted control-vector transduced Tcells in the presence of PGE2 led to a significant up-regulation of the inhibitory ligand CD94 as well as the adenosine producing ectoenzyme $\mathrm{CD} 73$ on $\mathrm{CD}^{+} \mathrm{T}$-cells. In accordance with the functional experiments described above, PDE4A overexpression counteracted this effect of PGE2 and completely abrogated upregulation of these inhibitory molecules (Figures 6A,B).

Apart from tumor-endogenous immunosuppression, exhaustion of T-cells also poses an impediment for the efficacy of adoptive immunotherapies. Thus, we tested the effects of PDE4Aoverexpression on T-cell exhaustion upon repetitive stimulation using anti-CD3/anti-CD28 coated beads and recombinant human IL-2 as in vitro stimuli. As expected, prolonged culture of control-vector transduced $\mathrm{CD}^{+}$and $\mathrm{CD}^{+}$T-cells led to the up-regulation of the exhaustion-associated cell surface markers CD244, PD-1 and TIM-3. Importantly, overexpression of PDE4A did not alter the phenotype of cultured $\mathrm{CD}^{+}$and CD8 ${ }^{+}$T-cells in comparison to control-vector transduced T-cells (Figure 6C and Supplementary Figure 6).

\section{DISCUSSION}

In this study we describe in a proof of principle in vitro study that overexpression of PDE4A in primary human effector $\mathrm{CD} 4^{+}$ and $\mathrm{CD}^{+}{ }^{+}$T-cells is sufficient to overcome the effects of cAMP, which acts as signaling hub for the suppressive function of soluble molecules such as PGE2 and adenosine as well as regulatory Tcells. PDE4A-transgenic T-cells were fully able to mount effector functions in the presence of PGE2 and adenosine and did not up-regulate PGE2-induced suppressive surface molecules such as CD73 and CD94. Furthermore, PDE4A overexpression also led to better activation of T-cells in the presence of Treg. Importantly, this manipulation did not affect T-cell functionality under nonsuppressive conditions. Taken together, we have shown that PDE4A is a safe and efficient immune checkpoint inhibitor, which efficiently disarms multiple suppressive entities. This knowledge could be essential for the improvement of adoptive T-cell therapies.
Adoptive T-cell therapies offer a promising directed approach to treat malignant diseases. Clinical trials have shown encouraging results especially in the therapy of hematological malignancies and first CAR T-cell therapies for refractory hematological diseases have been approved by the US Food and Drug Administration. While these developments highlight the enormous potential of adoptive T-cell therapy, not all trials have been successful so far and especially response rates in solid tumors have been poor (48). Consequently, further development of adoptive immunotherapy regimen is clearly warranted.

In principle, adoptively transferred T-cells have to fulfill at least four criteria to successfully target malignant cells: homing to the tumor, recognition of tumor cells, the mounting of effector functions under immunosuppressive conditions and abundant cytotoxicity. So far, most research has focused on the improvement of tumor-cell recognition and the concomitant full activation of the T-cells. In this regard, either tumor-antigen specific TCR or so called chimeric antigen receptors (CAR) have been introduced into patient T-cells (6). These antigenrecognition tools have been constantly refined, e.g., the use and recombination of different intracellular signaling domains derived from various co-stimulatory molecules and cytokine receptors (49) has led to the evolution of improved generations of CAR constructs. However, also strategies to optimize the other features described above have come into the spotlight in recent years (50).

In the light of the clinical efficacy of so-called checkpoint inhibitors it has become increasingly evident, that adoptive Tcell therapies, especially those targeted against solid tumors, might similarly profit from mechanisms which counteract immunosuppressive signals. In this regard, combination of CAR T-cells with checkpoint inhibitors has led to favorable results in pre-clinical models $(51,52)$ as well as clinical studies [reviewed in Yoon et al. (14)]. Generation of Tcells for adoptive transfer requires the ex vivo isolation, expansion and engineering of patient T-cells. It can be envisioned that molecules counteracting immunosuppressive signaling in T-cells, i.e., internal checkpoint inhibitors, can be additionally introduced during this process. In this regard, first attempts to target major immune checkpoints have been published. As early as 2002, Bollard et al. (53) could show that overexpression of a dominant-negative TGF-beta receptor strongly enhanced anti-tumor immunity in vitro, which was followed up by the same group in murine models (54). Similarly, approaches to modify PD1 signaling using overexpression of a dominant-negative PD-1 receptor (55), chimeric PD-1 fused to the intracellular signaling domain of CD28 (56), shRNAmediated knockdown (55) or CRISPR/Cas9-mediated knockout of PD-1 on adoptively transferred T-cells (57) has led to improved tumor recognition and clearance in murine models. Taken together these studies provide first important insights into the feasibility and the therapeutic potential of intrinsic immune checkpoints.

Malignant cells do not present as uniform cell-populations and among others the tumor-microenvironment and the acquisition of immunosuppressive mechanisms/immune 


\section{A}
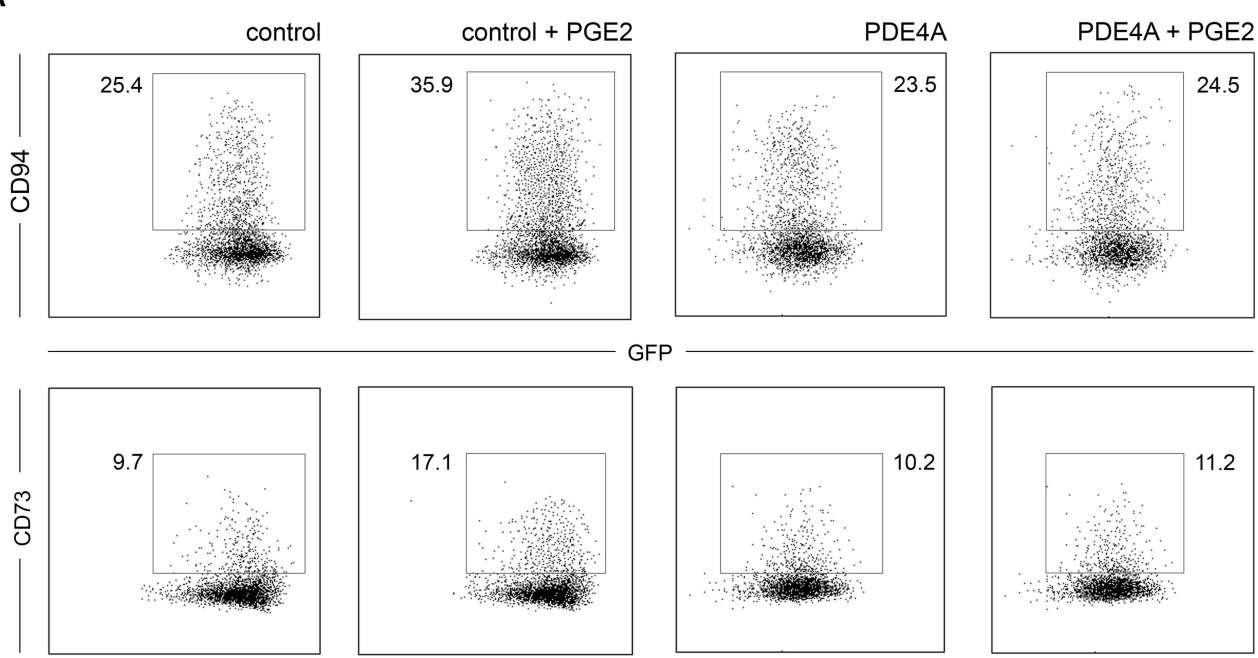

GFP

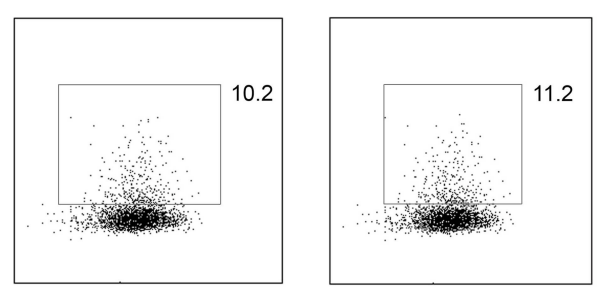

GFP

B
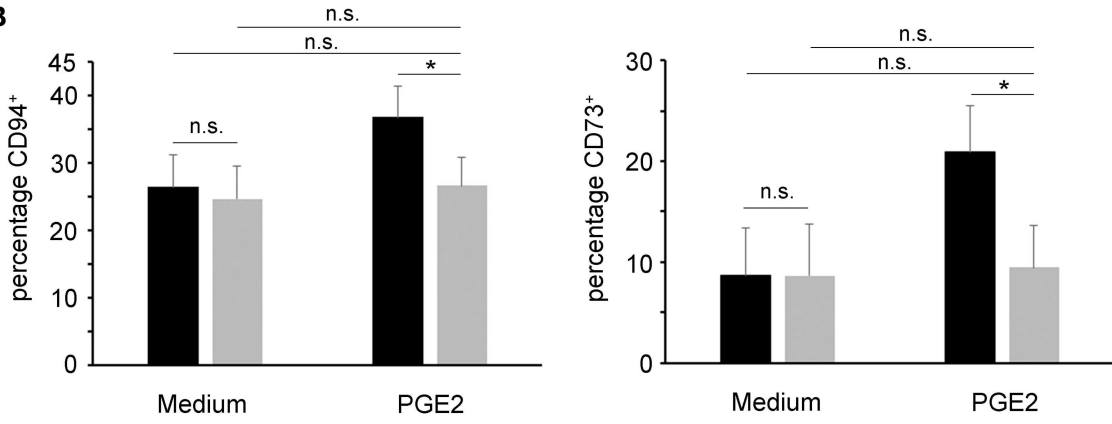

C

CD244

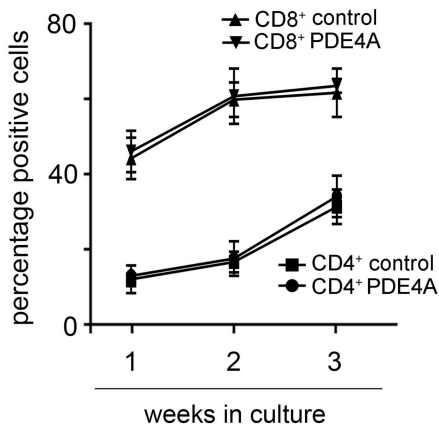

TIM-3

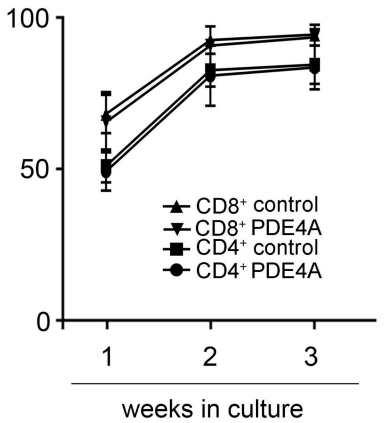

PD-1

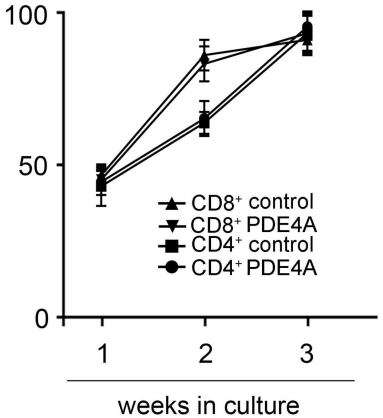

FIGURE 6 | Overexpression of PDE4A counteracts upregulation of inhibitory surface molecules under suppression by PGE2 but does not affect T-cell exhaustion in culture. (A) Control-vector transduced or PDE4A transduced human CD8 ${ }^{+}$T-cells were activated in the absence (left panels) or presence (right panels) of $200 \mathrm{nM}$ PGE2. After 7 days, surface expression of CD94 (upper lane) or CD73 (lower lane) were determined by flow cytometry. Dot blots from one representative experiment $(n=4)$ are depicted. (B) Statistical analysis of percentages of $\mathrm{CD}_{4}{ }^{+}$and $\mathrm{CD}_{3} 3^{+}$cells of the indicated specimen, black bars: control-vector transduced; gray bars: PDE4A transduced; mean values + SD are shown. (C) Control-vector transduced (squares and triangles) or PDE4A transduced (dots and inverted triangles) human $\mathrm{CD}^{+}$and $\mathrm{CD}^{+}{ }^{+}$T-cells were activated with agonistic anti-CD3/anti-CD28 antibodies and recombinant human IL-2 (10 U/mL) and restimulated every seven days. After each week of culture, surface expression of the exhaustion associated markers CD244, PD-1 and TIM-3 were measured by flow cytometry. Mean values \pm SD from three independent experiments are depicted. n.s., not significant; ${ }^{*} p<0.05$.

checkpoints may strongly vary between different tumor entities and even individuals affected from the same type of tumor (58). Increasing evidence exists that the landscape of immune-evasion is very complex and features many cellular and soluble entities as well as metabolic alterations (59). Among others, mechanisms which induce cAMP in tumor-infiltrating effector T-cells may 
play a prominent role (60). In this regard, the adenosine generating ectoenzymes $\operatorname{CD} 39(61,62)$ and $\operatorname{CD} 73(62)$ as well as the A2AR (63) have been proposed as immune checkpoints and expression of these molecules in tumor tissue has been correlated with poor prognosis (64). Similarly, COX-2 expression leading to high PGE2 levels has been described in different tumors $(32,33)$. Several studies have aimed to assess the efficacy of blockade of these mechanisms in combination with CAR T-cells. In this context, most researchers have evaluated the application of small molecule inhibitors to the above described molecules (65). While these approaches have led to significantly enhanced CAR T-cell activity in murine models, several obvious pitfalls exist. First, targeting a single mechanism in a complex immunosuppressive environment might not suffice to restore full CAR T-cell activity. Furthermore, both adenosine as well as PGE2 have a multitude of physiological functions other than immunoregulation, which might be similarly affected by systemic application of the respective inhibitors. Consequently, other approaches have aimed to target intracellular signaling pathways downstream of cAMP, most prominently the PKA. In one study, addition of the PKA-inhibitor Rp-8-Br-cAMPS could significantly improve T-cell responses in the presence of A2AR agonists. However, in line with our observations, this treatment could not fully abrogate the suppressive effects of cAMP (46). In a recent study, overexpression of a peptide blocking binding of PKA to the scaffold protein Ezrin was shown to improve T-cell activation under suppression by both PGE2 as well as adenosine in vitro and in vivo (66). However, multiple studies have pointed out that PKA signaling is not solely responsible for the T-cell suppressive function of cAMP, and PKA-independent signaling via other molecules such as Epac have been described (27, 32, 67, 68). Consequently, we have chosen to target cAMP as it acts as the central hub linking different extrinsic immunosuppressive mediators to several downstream signaling pathways. In our approach, we followed the strategy first described by Klein et al. (30), who used overexpression of a PDE to degrade cAMP in tTreg. These studies have led to important insights into the relevance of cAMP in Treg function. However, the possibility to use this mechanism as checkpoint inhibitor in effector T-cells has not been considered so far. In our experiments, overexpression of PDE4A in primary human $\mathrm{CD}^{+}$and $\mathrm{CD}^{+}{ }^{+}$-cells efficiently protected them from cAMP-mediated immunosuppression. PDE4A-transgenic T-cells were fully resistant to the suppressive effects of PGE2 and A2AR agonists in all activation and effector readouts measured. This included proliferation, the secretion of pro-inflammatory cytokines, the lysis of target cells as well as the up-regulation of inhibitory molecules. Similarly, effector T-cell responses under suppression by regulatory T-cells were significantly improved by PDE4A overexpression. Generation of transgenic T-cells for adoptive therapy relies on the genetic manipulation of donor lymphocytes which may contain residual Treg. Considering the data from Klein et al. (30) and from our study, our approach would thus not only protect effector T-cells from the suppressive effects of potential bystander Treg, but also efficiently disarm these cells. Importantly, PDE4A-transgenic T-cells did not show increased reactivity in comparison to control-vector transduced T-cells under non-suppressive conditions, thus limiting the potential for increased immune mediated side effects during therapy. Importantly, overexpression of PDE4A also did not affect viability of the transgenic T-cells. Furthermore, the use of a human physiological enzyme should also minimize the potential immunogenicity of the introduced molecule, which could in principle limit the efficacy of the adoptively transferred T-cells. It must also be considered that 11 different PDE families have been characterized in human cells so far which all show different affinity and specificity toward cAMP (69). It remains to be assessed, whether overexpression of PDE4A is the optimal approach, or whether other PDEs show an even better profile as immune checkpoint inhibitors.

From these presented points it can be concluded that the described approach thus offers the possibility for direct translation into therapeutic settings. However, our observations also shed light on basic principles of T-cell biology. Indeed, the selective abrogation of cAMP signaling by the overexpressed PDE4A provides a model system to study basic biological principles of this pathway for T-cell activation under nonsuppressive and suppressive conditions. First, abrogation of cAMP signaling in $\mathrm{CD}^{+}$and $\mathrm{CD}^{+}$effector T-cells did not influence major effector functions under non-suppressive conditions. Thus, the induction of cAMP does not constitute an intrinsic feedback mechanisms that is required for physiological T-cell homeostasis, but rather a system which allows inhibition of T-cell activation in immunosuppressive environments generated by tolerogenic myeloid and lymphoid cells. This hypothesis is also supported in our long term in vitro culture experiments of the transduced T-cells. There, we found that PDE4A-transgenic T-cells were not more prone to up-regulate surface markers of T-cell exhaustion, demonstrating that cAMP signaling is not intrinsically involved in T-cell exhaustion upon repetitive activation. Furthermore, our experiments also provide intriguing insights into the interplay between tTreg and Teff and the importance of cAMP signaling in this context. A large body of literature exists which shows that Treg utilize different molecular mechanisms which subsequently trigger different intracellular signaling cascades in Teff to suppress the activation of the latter (70). Among them, the generation of extracellular adenosine by the ectoenzymes CD39 and CD73 $(20,21)$ as well as the direct transfer of cAMP via gap junctions (22) can lead to an increase in intracellular cAMP in Teff. Notably, in our experiments, the abrogation of cAMP signaling by overexpression of PDE4A could only partially overcome the suppression of Teff proliferation in co-culture with Treg. Especially at high Treg: Teff ratios, PDE4A-transgenic T-cells showed no or only slightly improved proliferation compared to control-vector transduced T-cells. The overexpression levels of PDE4A reached with our vector system were able to robustly abrogate cAMP levels even under high adenylate cyclase activity. Thus, it seems improbable that tTreg might overwhelm the transgenic PDE4A by abundant induction and transfer of cAMP into Teff. Consequently, our observations suggest that proliferation of Teff is suppressed by Treg using additional mechanisms other than cAMP. In contrast, production of cytokines such as IL-2 and IFN- $\gamma$ is 
highly sensitive to cAMP increases but independent of other Treg mechanisms. It has been amply demonstrated that different T-cell effector functions such as proliferation and cytokine production are governed by different intracellular signaling pathways (71). Thus, it seems conceivable that suppression of these effector functions might also require different inhibitory signals. The described multitude of suppressive Treg mechanisms might serve to selectively suppress distinct Teff functions. Further studies to assess this intriguing hypothesis are clearly warranted and may help to define novel strategies how to fine-tune the effects of Treg.

In conclusion we here show in a proof of principle study that overexpression of a cAMP-degrading phosphodiesterase can fully protect effector T-cells from suppression by diverse soluble mediators such as PGE2 and adenosine in vitro. Furthermore, PDE-transgenic T-cells show improved responses in the presence of regulatory T-cells. Thus, our approach constitutes a novel internal checkpoint inhibitor against multiple immunosuppressive entities to improve adoptive T-cell therapy. It will be imperative to define further central signaling hubs of T-cell suppression and strategies to counteract their function. This is especially important in the light of recent data, that tumors can develop resistance to blockade of singular immune checkpoints by the use of other immunosuppressive entities (72). Thus, use of PDE4A also in combination with other internal immune checkpoint inhibitors could significantly improve the efficacy of adoptive T-cell regimen.

\section{DATA AVAILABILITY}

All datasets generated for this study are included in the manuscript and/or the Supplementary Files.

\section{REFERENCES}

1. Stewart TJ, Abrams SI. How tumours escape mass destruction. Oncogene. (2008) 27:5894-903. doi: 10.1038/onc.2008.268

2. Vinay DS, Ryan EP, Pawelec G, Talib WH, Stagg J, Elkord E, et al. Immune evasion in cancer: mechanistic basis and therapeutic strategies. Semin Cancer Biol. (2015) 35:S185-98. doi: 10.1016/j.semcancer.2015.03.004

3. Hodi FS, O’Day SJ, McDermott DF, Weber RW, Sosman JA, Haanen JB, et al. Improved survival with ipilimumab in patients with metastatic melanoma. $N$ Engl J Med. (2010) 363:711-23. doi: 10.1056/NEJMoa1003466

4. Ott PA, Hodi FS, Robert C. CTLA-4 and PD-1/PD-L1 blockade: new immunotherapeutic modalities with durable clinical benefit in melanoma patients. Clin Cancer Res. (2013) 19:5300-9. doi: 10.1158/1078-0432.CCR-13-0143

5. Bonini C, Mondino A. Adoptive T-cell therapy for cancer: the era of engineered T cells. Eur J Immunol. (2015) 45:2457-69. doi: 10.1002/eji.201545552

6. Duong CP, Yong CS, Kershaw MH, Slaney CY, Darcy PK. Cancer immunotherapy utilizing gene-modified $\mathrm{T}$ cells: from the bench to the clinic. Mol Immunol. (2015) 67(2 Pt A):46-57. doi: 10.1016/j.molimm.2014. 12.009

7. Maude SL, Laetsch TW, Buechner J, Rives S, Boyer M, Bittencourt H, et al. Tisagenlecleucel in children and young adults with B-cell lymphoblastic leukemia. N Engl J Med. (2018) 378:439-48. doi: 10.1056/NEJMoa1709866

\section{ETHICS STATEMENT}

The study was approved by the local ethics committee of the Medical University of Vienna (EC number 1724/2012) and conducted according to the Declaration of Helsinki (1969, including current revisions) of the World Medical Association. Blood was drawn after obtaining written informed consent of the study participants.

\section{AUTHOR CONTRIBUTIONS}

$\mathrm{KS}$ and RM planned the project and designed experiments. $\mathrm{KS}, \mathrm{KG}, \mathrm{RS}, \mathrm{MG}$, and $\mathrm{LZ}$ performed all described functional experiments and flow cytometric analyses. MT and EZ-B performed cAMP assays. JL and PS assisted with cloning of the PDE4A construct and provided reagents. DT and WP assisted with thymidine incorporation assays. IS assisted with flow cytometric analyses and provided reagents. KS and RM wrote the manuscript. All authors critically read and approved the manuscript.

\section{FUNDING}

This work was supported by grants from the Medical Scientific Fund of the Mayor of the City of Vienna (Grant 13040 and 15099), from the Austrian Society for Laboratory Medicine and Clinical Chemistry and from the Austrian Science Funds (FWF, projects P29654-B30 and SFB-F4609).

\section{SUPPLEMENTARY MATERIAL}

The Supplementary Material for this article can be found online at: https://www.frontiersin.org/articles/10.3389/fimmu. 2019.01790/full\#supplementary-material

8. Neelapu SS, Locke FL, Go WY. CAR T-cell therapy in large Bcell lymphoma. N Engl J Med. (2018) 378:1065. doi: 10.1056/NEJMc18 00913

9. Sadelain M, Riviere I, Riddell S. Therapeutic T cell engineering. Nature. (2017) 545:423-31. doi: 10.1038/nature22395

10. Whiteside TL. Disarming suppressor cells to improve immunotherapy. Cancer Immunol Immunother. (2012) 61:283-8. doi: 10.1007/s00262-011-1171-7

11. Lloyd A, Vickery ON, Laugel B. Beyond the antigen receptor: editing the genome of T-cells for cancer adoptive cellular therapies. Front Immunol. (2013) 4:221. doi: 10.3389/fimmu.2013.00221

12. Sun C, Dotti G, Savoldo B. Utilizing cell-based therapeutics to overcome immune evasion in hematologic malignancies. Blood. (2016) 127:3350-9. doi: 10.1182/blood-2015-12-629089

13. Salter I, Pont MJ, Riddell SR. Chimeric antigen receptor-modified T cells: CD19 and the road beyond. Blood. (2018) 131:2621-9. doi: 10.1182/blood-2018-01-785840

14. Yoon DH, Osborn MJ, Tolar J, Kim CJ. Incorporation of immune checkpoint blockade into chimeric antigen receptor $\mathrm{T}$ cells (CAR-Ts): combination or built-in CAR-T. Int J Mol Sci. (2018) 19:E340. doi: 10.3390/ijms190 20340

15. Harris SG, Padilla J, Koumas L, Ray D, Phipps RP. Prostaglandins as modulators of immunity. Trends Immunol. (2002) 23:144-50. doi: 10.1016/S1471-4906(01)02154-8 
16. Huang S, Apasov S, Koshiba M, Sitkovsky M. Role of A2a extracellular adenosine receptor-mediated signaling in adenosine-mediated inhibition of T-cell activation and expansion. Blood. (1997) 90:1600-10.

17. Loza MJ, Foster S, Peters SP, Penn RB. Beta-agonists modulate T-cell functions via direct actions on type 1 and type 2 cells. Blood. (2006) 107:2052-60. doi: 10.1182/blood-2005-08-3265

18. Barisione G, Baroffio M, Crimi E, Brusasco V. Beta-adrenergic agonists. Pharmaceuticals. (2010) 3:1016-44. doi: 10.3390/ph3041016

19. Hill SJ. Distribution, properties, and functional characteristics of three classes of histamine receptor. Pharmacol Rev. (1990) 42:45-83.

20. Borsellino G, Kleinewietfeld M, Di Mitri D, Sternjak A, Diamantini A, Giometto R, et al. Expression of ectonucleotidase CD39 by Foxp3 ${ }^{+}$Treg cells: hydrolysis of extracellular ATP and immune suppression. Blood. (2007) 110:1225-32. doi: 10.1182/blood-2006-12-064527

21. Deaglio S, Dwyer KM, Gao W, Friedman D, Usheva A, Erat A, et al. Adenosine generation catalyzed by CD39 and CD73 expressed on regulatory T cells mediates immune suppression. J Exp Med. (2007) 204:1257-65. doi: 10.1084/jem.20062512

22. Bopp T, Becker C, Klein M, Klein-Hessling S, Palmetshofer A, Serfling $\mathrm{E}$, et al. Cyclic adenosine monophosphate is a key component of regulatory T cell-mediated suppression. J Exp Med. (2007) 204:1303-10. doi: 10.1084 jem.20062129

23. Rueda CM, Jackson CM, Chougnet CA. Regulatory T-cell-mediated suppression of conventional T-cells and dendritic cells by different cAMP intracellular pathways. Front Immunol. (2016) 7:216. doi: 10.3389/fimmu.2016.00216

24. Mosenden R, Tasken K. Cyclic AMP-mediated immune regulation-overview of mechanisms of action in T cells. Cell Signal. (2011) 23:1009-16. doi: 10.1016/j.cellsig.2010.11.018

25. Huang B, Zhao J, Lei Z, Shen S, Li D, Shen GX, et al. miR-142-3p restricts cAMP production in $\mathrm{CD} 4^{+} \mathrm{CD} 25^{-} \mathrm{T}$ cells and $\mathrm{CD} 4{ }^{+} \mathrm{CD} 25^{+}$ TREG cells by targeting AC9 mRNA. EMBO Rep. (2009) 10:180-5. doi: $10.1038 /$ embor.2008.224

26. Sugimoto N, Oida T, Hirota K, Nakamura K, Nomura T, Uchiyama T, et al. Foxp3-dependent and -independent molecules specific for CD25 ${ }^{+} \mathrm{CD} 4{ }^{+}$ natural regulatory $\mathrm{T}$ cells revealed by DNA microarray analysis. Int Immunol. (2006) 18:1197-209. doi: 10.1093/intimm/dxl060

27. Bryce PJ, Dascombe MJ, Hutchinson IV. Immunomodulatory effects of pharmacological elevation of cyclic AMP in T lymphocytes proceed via a protein kinase A independent mechanism. Immunopharmacology. (1999) 41:139-46. doi: 10.1016/S0162-3109(98)00060-5

28. Vang G, Housley W, Dong H, Basole C, Ben-Sasson SZ, Kream BE, et al. Regulatory T-cells and cAMP suppress effector T-cells independently of PKA-CREM/ICER: a potential role for Epac. Biochem J. (2013) 456:463-73. doi: 10.1042/BJ20130064

29. Bopp T, Dehzad N, Reuter S, Klein M, Ullrich N, Stassen M, et al. Inhibition of cAMP degradation improves regulatory $\mathrm{T}$ cell-mediated suppression. $J$ Immunol. (2009) 182:4017-24. doi: 10.4049/jimmunol.0803310

30. Klein M, Vaeth M, Scheel T, Grabbe S, Baumgrass R, Berberich-Siebelt F, et al. Repression of cyclic adenosine monophosphate upregulation disarms and expands human regulatory T cells. J Immunol. (2012) 188:1091-7. doi: 10.4049/jimmunol.1102045

31. Sakkas LI, Mavropoulos A, Bogdanos DP. Phosphodiesterase 4 inhibitors in immune-mediated diseases: mode of action, clinical applications, current and future perspectives. Curr Med Chem. (2017) 24:3054-67. doi: 10.2174/0929867324666170530093902

32. Wang D, Dubois RN. The role of COX-2 in intestinal inflammation and colorectal cancer. Oncogene. (2010) 29:781-8. doi: 10.1038/onc.2009.421

33. Miglietta A, Toselli M, Ravarino N, Vencia W, Chiecchio A, Bozzo F, et al. COX-2 expression in human breast carcinomas: correlation with clinicopathological features and prognostic molecular markers. Expert Opin Ther Targets. (2010) 14:655-64. doi: 10.1517/14728222.2010.486792

34. Bastid J, Regairaz A, Bonnefoy N, Dejou C, Giustiniani J, Laheurte C, et al. Inhibition of CD39 enzymatic function at the surface of tumor cells alleviates their immunosuppressive activity. Cancer Immunol Res. (2015) 3:254-65. doi: 10.1158/2326-6066.CIR-14-0018

35. Pulte D, Furman RR, Broekman MJ, Drosopoulos JH, Ballard HS, Olson KE, et al. CD39 expression on T lymphocytes correlates with severity of disease in patients with chronic lymphocytic leukemia. Clin Lymphoma Myeloma Leuk. (2011) 11:367-72. doi: 10.1016/j.clml.2011.06.005

36. Serra S, Horenstein AL, Vaisitti T, Brusa D, Rossi D, Laurenti L, et al. CD73-generated extracellular adenosine in chronic lymphocytic leukemia creates local conditions counteracting drug-induced cell death. Blood. (2011) 118:6141-52. doi: 10.1182/blood-2011-08-374728

37. Jie HB, Gildener-Leapman N, Li J, Srivastava RM, Gibson SP, Whiteside $\mathrm{TL}$, et al. Intratumoral regulatory $\mathrm{T}$ cells upregulate immunosuppressive molecules in head and neck cancer patients. Br J Cancer. (2013) 109:2629-35. doi: 10.1038/bjc.2013.645

38. Wei T, Zhang J, Qin Y, Wu Y, Zhu L, Lu L, et al. Increased expression of immunosuppressive molecules on intratumoral and circulating regulatory $\mathrm{T}$ cells in non-small-cell lung cancer patients. Am J Cancer Res. (2015) 5:2190201.

39. Timperi E, Pacella I, Schinzari V, Focaccetti C, Sacco L, Farelli F, et al. Regulatory $\mathrm{T}$ cells with multiple suppressive and potentially pro-tumor activities accumulate in human colorectal cancer. Oncoimmunology. (2016) 5:e1175800. doi: 10.1080/2162402X.2016.1175800

40. Hilchey SP, Kobie JJ, Cochran MR, Secor-Socha S, Wang JC, Hyrien O, et al. Human follicular lymphoma $\mathrm{CD} 9^{+}$-infiltrating $\mathrm{T}$ cells contribute to adenosine-mediated T cell hyporesponsiveness. J Immunol. (2009) 183:615766. doi: 10.4049/jimmunol.0900475

41. Szczepanski MJ, Szajnik M, Czystowska M, Mandapathil M, Strauss L, Welsh $\mathrm{A}$, et al. Increased frequency and suppression by regulatory $\mathrm{T}$ cells in patients with acute myelogenous leukemia. Clin Cancer Res. (2009) 15:3325-32. doi: 10.1158/1078-0432.CCR-08-3010

42. Schmetterer KG, Haiderer D, Leb-Reichl VM, Neunkirchner A, Jahn-Schmid B, Kung HJ, et al. Bet v 1-specific T-cell receptor/forkhead box protein 3 transgenic $\mathrm{T}$ cells suppress Bet $\mathrm{v}$ 1-specific T-cell effector function in an activation-dependent manner. J Allergy Clin Immunol. (2010) 127:238-45. doi: 10.1016/j.jaci.2010.10.023

43. Derdak SV, Kueng HJ, Leb VM, Neunkirchner A, Schmetterer KG, Bielek E, et al. Direct stimulation of $\mathrm{T}$ lymphocytes by immunosomes: virus-like particles decorated with $\mathrm{T}$ cell receptor/CD3 ligands plus costimulatory molecules. Proc Natl Acad Sci USA. (2006) 103:13144-9. doi: 10.1073/pnas.0602283103

44. Waclavicek M, Majdic O, Stulnig T, Berger M, Baumruker T, Knapp W, et al. T cell stimulation via CD47: agonistic and antagonistic effects of CD47 monoclonal antibody 1/1A4. J Immunol. (1997) 159:5345-54.

45. Cossarizza A, Chang HD, Radbruch A, Akdis M, Andra I, Annunziato F, et al. Guidelines for the use of flow cytometry and cell sorting in immunological studies. Eur J Immunol. (2017) 47:1584-797. doi: 10.1002/eji.2016 46632

46. Raskovalova T, Lokshin A, Huang X, Su Y, Mandic M, Zarour HM, et al. Inhibition of cytokine production and cytotoxic activity of human antimelanoma specific $\mathrm{CD}^{+}$and $\mathrm{CD}^{+}{ }^{+} \mathrm{T}$ lymphocytes by adenosineprotein kinase A type I signaling. Cancer Res. (2007) 67:5949-56. doi: 10.1158/0008-5472.CAN-06-4249

47. Zeddou M, Greimers R, de Valensart N, Nayjib B, Tasken K, Boniver $\mathrm{J}$, et al. Prostaglandin E2 induces the expression of functional inhibitory CD94/NKG2A receptors in human $\mathrm{CD}^{+} \mathrm{T}$ lymphocytes by a cAMPdependent protein kinase A type I pathway. Biochem Pharmacol. (2005) 70:714-24. doi: 10.1016/j.bcp.2005.05.015

48. D’Aloia MM, Zizzari IG, Sacchetti B, Pierelli L, Alimandi M. CAR-T cells: the long and winding road to solid tumors. Cell Death Dis. (2018) 9:282. doi: 10.1038/s41419-018-0278-6

49. Kagoya Y, Tanaka S, Guo T, Anczurowski M, Wang CH, Saso K, et al. A novel chimeric antigen receptor containing a JAK-STAT signaling domain mediates superior antitumor effects. Nat Med. (2018) 24:352-9. doi: 10.1038/nm.4478

50. Ghoneim HE, Zamora AE, Thomas PG, Youngblood BA. Cell-intrinsic barriers of T cell-based immunotherapy. Trends Mol Med. (2016) 22:1000-11. doi: 10.1016/j.molmed.2016.10.002

51. John LB, Devaud C, Duong CP, Yong CS, Beavis PA, Haynes NM, et al. Anti-PD-1 antibody therapy potently enhances the eradication of established tumors by gene-modified T cells. Clin Cancer Res. (2013) 19:5636-46. doi: 10.1158/1078-0432.CCR-13-0458

52. Moon EK, Ranganathan R, Eruslanov E, Kim S, Newick K, O’Brien $\mathrm{S}$, et al. Blockade of programmed death 1 augments the ability of 
human $\mathrm{T}$ cells engineered to target NY-ESO-1 to control tumor growth after adoptive transfer. Clin Cancer Res. (2016) 22:436-47. doi: 10.1158/1078-0432.CCR-15-1070

53. Bollard CM, Rossig C, Calonge MJ, Huls MH, Wagner HJ, Massague J, et al. Adapting a transforming growth factor beta-related tumor protection strategy to enhance antitumor immunity. Blood. (2002) 99:317987. doi: 10.1182/blood.V99.9.3179

54. Foster E, Dotti G, Lu A, Khalil M, Brenner MK, Heslop HE, et al. Antitumor activity of EBV-specific $\mathrm{T}$ lymphocytes transduced with a dominant negative TGF-beta receptor. J Immunother. (2008) 31:500-5. doi: 10.1097/CJI.0b013e318177092b

55. Cherkassky L, Morello A, Villena-Vargas J, Feng Y, Dimitrov DS, Jones $\mathrm{DR}$, et al. Human CAR $\mathrm{T}$ cells with cell-intrinsic PD-1 checkpoint blockade resist tumor-mediated inhibition. J Clin Invest. (2016) 126:3130-44. doi: 10.1172/JCI83092

56. Liu X, Ranganathan R, Jiang S, Fang C, Sun J, Kim S, et al. A chimeric switch-receptor targeting PD1 augments the efficacy of second-generation CAR T cells in advanced solid tumors. Cancer Res. (2016) 76:1578-90. doi: 10.1158/0008-5472.CAN-15-2524

57. Ren J, Liu X, Fang C, Jiang S, June CH, Zhao Y. Multiplex genome editing to generate universal CAR T cells resistant to PD1 inhibition. Clin Cancer Res. (2017) 23:2255-66. doi: 10.1158/1078-0432.CCR-16-1300

58. Thorsson V, Gibbs DL, Brown SD, Wolf D, Bortone DS, Ou Yang TH, et al. The immune landscape of cancer. Immunity. (2018) 48:812-30.e14. doi: 10.1016/j.immuni.2018.03.023

59. Pacella I, Procaccini C, Focaccetti C, Miacci S, Timperi E, Faicchia D, et al. Fatty acid metabolism complements glycolysis in the selective regulatory T cell expansion during tumor growth. Proc Natl Acad Sci USA. (2018) 115:E6546-E6555. doi: 10.1073/pnas.1720113115

60. Leone RD, Emens LA. Targeting adenosine for cancer immunotherapy. $J$ Immunother Cancer. (2018) 6:57. doi: 10.1186/s40425-018-0360-8

61. Bastid J, Cottalorda-Regairaz A, Alberici G, Bonnefoy N, Eliaou JF, Bensussan A. ENTPD1/CD39 is a promising therapeutic target in oncology. Oncogene. (2013) 32:1743-51. doi: 10.1038/onc.2012.269

62. Allard B, Longhi MS, Robson SC, Stagg J. The ectonucleotidases CD39 and CD73: novel checkpoint inhibitor targets. Immunol Rev. (2017) 276:121-44. doi: 10.1111/imr.12528

63. Leone RD, Lo YC, Powell JD. A2aR antagonists: next generation checkpoint blockade for cancer immunotherapy. Comput Struct Biotechnol J. (2015) 13:265-72. doi: 10.1016/j.csbj.2015.03.008

64. Gaudreau PO, Allard B, Turcotte M, Stagg J. CD73-adenosine reduces immune responses and survival in ovarian cancer patients. Oncoimmunology. (2016) 5:e1127496. doi: 10.1080/2162402X.2015.1127496
65. Beavis PA, Henderson MA, Giuffrida L, Mills JK, Sek K, Cross RS, et al. Targeting the adenosine $2 \mathrm{~A}$ receptor enhances chimeric antigen receptor $\mathrm{T}$ cell efficacy. J Clin Invest. (2017) 127:929-41. doi: 10.1172/JCI89455

66. Newick K, O’Brien S, Sun J, Kapoor V, Maceyko S, Lo A, et al. Augmentation of CAR T-cell trafficking and antitumor efficacy by blocking protein kinase A localization. Cancer Immunol Res. (2016) 4:541-51. doi: 10.1158/2326-6066.CIR-15-0263

67. Staples J, Bergmann M, Tomita K, Houslay MD, McPhee I, Barnes PJ, et al. Adenosine 3',5'-cyclic monophosphate (cAMP)-dependent inhibition of IL5 from human $\mathrm{T}$ lymphocytes is not mediated by the cAMP-dependent protein kinase. J Immunol A. (2001) 167:2074-80. doi: 10.4049/jimmunol.167. 4.2074

68. Fuld S, Borland G, Yarwood SJ. Elevation of cyclic AMP in Jurkat T-cells provokes distinct transcriptional responses through the protein kinase A (PKA) and exchange protein activated by cyclic AMP (EPAC) pathways. Exp Cell Res. (2005) 309:161-73. doi: 10.1016/j.yexcr.2005.05.016

69. Keravis T, Lugnier C. Cyclic nucleotide phosphodiesterase (PDE) isozymes as targets of the intracellular signalling network: benefits of PDE inhibitors in various diseases and perspectives for future therapeutic developments. Br J Pharmacol. (2012) 165:1288-305. doi: 10.1111/j.1476-5381.2011. 01729.x

70. Schmetterer KG, Neunkirchner A, Pickl WF. Naturally occurring regulatory T cells: markers, mechanisms, and manipulation. FASEB J. (2012) 26:2253-76. doi: 10.1096/fj.11-193672

71. Guy CS, Vignali KM, Temirov J, Bettini ML, Overacre AE, Smeltzer M, et al. Distinct TCR signaling pathways drive proliferation and cytokine production in T cells. Nat Immunol. (2013) 14:262-70. doi: 10.1038/ni.2538

72. Jenkins RW, Barbie DA, Flaherty KT. Mechanisms of resistance to immune checkpoint inhibitors. Br J Cancer. (2018) 118:9-16. doi: 10.1038/bjc.2017.434

Conflict of Interest Statement: The authors declare that the research was conducted in the absence of any commercial or financial relationships that could be construed as a potential conflict of interest.

Copyright (c) 2019 Schmetterer, Goldhahn, Ziegler, Gerner, Schmidt, Themanns, Zebedin-Brandl, Trapin, Leitner, Pickl, Steinberger, Schwarzinger and Marculescu. This is an open-access article distributed under the terms of the Creative Commons Attribution License (CC BY). The use, distribution or reproduction in other forums is permitted, provided the original author(s) and the copyright owner(s) are credited and that the original publication in this journal is cited, in accordance with accepted academic practice. No use, distribution or reproduction is permitted which does not comply with these terms. 